\title{
Ubiquitylation as a Rheostat for TCR Signaling: From Targeted Approaches Toward Global Profiling
}

\author{
Claire E. O'Leary, Emma L. Lewis and Paula M. Oliver* \\ Perelman School of Medicine, University of Pennsylvania, Philadelphia, PA, USA
}

T cell receptor (TCR) signaling must be precisely tuned to limit collateral damage and prevent reactivity to self, while still allowing robust protective immune responses that control pathogen invasion. One process that can be used to promote, modify, or terminate TCR signaling is ubiquitylation. During ubiquitylation, ubiquitin is covalently attached to target proteins through a multistep process, in which E3 ubiquitin ligases promote the formation of ubiquitin chains on selected substrates. Ubiquitylation can facilitate protein-protein interactions, direct a protein to a specific subcellular location, or initiate protein destruction. Like phosphorylation, ubiquitylation is a reversible process - deubiquitylating enzymes counteract ligase function by removing ubiquitin chains.

OPEN ACCESS

Edited by:

Eric Huseby,

University of Massachusetts Medical

School, USA

Reviewed by:

Paula Kavathas,

Yale University School of Medicine,

USA

Silvia Deaglio,

University of Turin, Italy

*Correspondence:

Paula M. Oliver

paulao@mail.med.upenn.edu

Specialty section:

This article was submitted to T Cell

Biology, a section of the

journal Frontiers in Immunology

Received: 18 September 2015

Accepted: 26 November 2015

Published: 16 December 2015

Citation:

O'Leary CE, Lewis EL and Oliver PM (2015) Ubiquitylation as a Rheostat for TCR Signaling: From Targeted Approaches Toward Global Profiling.

Front. Immunol. 6:618.

doi: 10.3389/fimmu.2015.00618
This reversibility also allows for ubiquitin chain "editing." Based on an emerging wealth of information from genetic loss-of-function studies showing that deregulation of ubiquitylation pathways leads to immune dysfunction, it has become increasingly apparent that the dynamic process of ubiquitylation is critical for normal immune cell function. In this review, we will describe how ubiquitylation acts as a key modulator and integrator of signaling downstream of TCR engagement. Specifically, we highlight the known roles of the substrate-specific E3 ligases and deubiquitylating enzymes in TCR signaling and $T$ cell activation. While it is clear that ubiquitin enzymes tune $T$ cell signaling and $T$ cell function, elucidating the molecular mechanisms by which these proteins modulate $T$ cells has met with significant challenges. Identifying substrates of these enzymes has been a particular challenge, and thus substrates of many E3 ligases and deubiquitylating enzymes remain largely unknown. To that end, we discuss the promise, and some practical considerations, of using proteomics-based techniques for unbiased identification of putative substrates of ubiquitin cascade proteins within primary $T$ cells. These methods provide an exciting opportunity for further defining how TCR signals are regulated and for identifying new targets for therapeutic modulation.

Keywords: ubiquitin, TCR signaling, proteomics, ubiquitin-protein ligases, T cell

\section{INTRODUCTION}

$\mathrm{T}$ cells are key organizers of the immune response. During an immune response, $\mathrm{CD} 4^{+} \mathrm{T}$ helper cells direct the response of other cell types through the production of cytokines, while $\mathrm{CD} 8^{+}$cytotoxic $\mathrm{T}$ cells mediate direct elimination of infected or altered-self cells. Both $\mathrm{CD} 4^{+}$and $\mathrm{CD} 8^{+} \mathrm{T}$ cells promote elimination of pathogens through a variety of means and provide protection against 
re-exposure by establishing long-lasting memory cell populations. To acquire these protective functions, T cells are first activated via their T cell receptor (TCR) by an antigen-presenting cell (APC) presenting an antigenic peptide-MHC (pMHC). During activation, quantitative (strength) as well as qualitative (presence or absence) signals are integrated to specifically tailor the $T$ cell response to the host's need to clear a specific type of pathogen or limit collateral damage from other responding immune cells. The combination of signals from engagement of the TCR, costimulatory molecules, and cytokine receptors (also known as, respectively, signals one, two, and three) allows appropriate, contextual activation and differentiation of T cells (1-4). Depending on the type of pathogen encountered, $\mathrm{CD} 8^{+} \mathrm{T}$ cells and distinct $\mathrm{T}$ helper subsets play more or less important roles in directing the immune response.

Inappropriate signaling downstream of TCR/co-stimulatory molecule engagement can lead a $\mathrm{T}$ cell to respond aberrantly, resulting in hypo- or hyper-responsiveness to antigenic stimulation (5-7). The expression levels and function of cellular proteins that relay signals initiated downstream of TCR and co-stimulatory molecule engagement are therefore tightly regulated to prevent inappropriate $\mathrm{T}$ cell responses. Post-translational modifications play critical roles in regulating these signal transduction pathways. In this regard, phosphorylation and dephosphorylation events have been a primary focus of research on TCR signaling pathways, particularly TCR-proximal signaling. However, there is growing appreciation that covalent attachment of the $8-\mathrm{kDa}$ protein ubiquitin, either single or in chains, is another key post-translational modification driving $\mathrm{T}$ cell signaling and fate decisions.

The most commonly considered outcome of ubiquitylation is protein degradation via the proteasome. However, monoubiquitylation or polyubiquitylation of accessible target protein lysines can alter protein fate and function in diverse ways, resulting in protein degradation, activation or inhibition of function, altered trafficking, or providing a scaffold for protein-protein interactions $(8,9)$. In $\mathrm{T}$ cells, ubiquitylation can affect $\mathrm{T}$ cell activation and anergy, as well as helper $\mathrm{T}$ cell differentiation, cytokine production, and cell cycle progression $(10,11)$.

Conjugation of ubiquitin to lysines on target proteins (substrates) occurs in a series of steps, illustrated in Figure 1A. First, ubiquitin is activated in an ATP-dependent manner by conjugation to an E1, or ubiquitin activating enzyme. Second, in a trans-thiolation reaction, ubiquitin is transferred from the E1 to the catalytic cysteine of an E2, or ubiquitin conjugating enzyme. The ubiquitin-conjugated E2 then interacts with an E3 ubiquitin ligase, to allow ubiquitylation on a lysine residue of a substrate $(8,12)$. E3 ubiquitin ligases bring substrate specificity to this reaction. There are two types of E3 ubiquitin ligases: those that have intrinsic catalytic activity, homologous to E6AP carboxyl terminus (HECT) type and really interesting new gene (RING)between-RING (RBR) ligases, and those that do not, RING or U-box ligases (13). RING or U-box E3 ligases serve a scaffolding function, bringing ubiquitin-loaded E2 into close proximity to target protein lysines to facilitate covalent bond formation between the target lysine and the C-terminal glycine of ubiquitin. HECT-type ligases also bind to substrate and ubiquitin-loaded $\mathrm{E} 2$, but, in a second trans-thiolation reaction, ubiquitin is passed from the catalytic cysteine of the E2 to the catalytic cysteine of the E3, which then catalyzes ubiquitylation of the target lysine directly (14). RBR ligases have HECT-like catalytic activity in one RING domain, while the other retains the more common RING function, namely, the capacity to bind an E2 (15).

Ubiquitylation of a protein substrate can result in monoubiquitylation - the addition of a single ubiquitin to one or many accessible lysines of the substrates (known as multi-monoubiquitylation) - or can lead to the formation of polyubiquitin chains on the substrate (Figure 1B). These distinct post-translational modifications are recognized as unique signals by proteins containing ubiquitin-binding domains (16). Polyubiquitylation
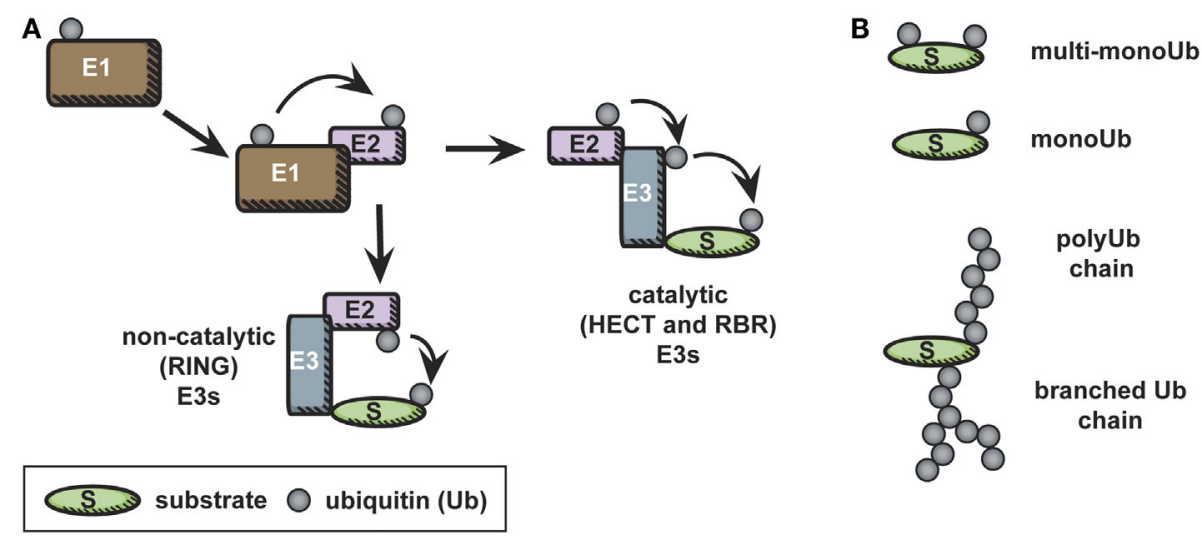

FIGURE 1 | The ubiquitin cascade. (A) Free ubiquitin is activated in an ATP-dependent manner by conjugation to an E1. Subsequently, in a trans-thiolation reaction, ubiquitin is transferred from the $\mathrm{E} 1$ to the catalytic cysteine of an E2. The ubiquitin-conjugated E2 then interacts with an E3 ubiquitin ligase, to allow ubiquitylation on a lysine residue of a substrate. In the case of catalytic E3 ligases, an additional trans-thiolation reaction occurs to transfer ubiquitin from the E2 catalytic cysteine to the E3 catalytic cysteine. The E3 then mediates covalent bond formation between the substrate and ubiquitin. (B) Ubiquitylation is a diverse modification, and distinct types of ubiquitylation - monoubiquitylation, multi-monoubiquitylation, and various polyubiquitylation linkages - are recognized by distinct ubiquitin-binding domains, leading to diverse final outcomes for the ubiquitylated protein. 
occurs when ubiquitin is processively conjugated to itself via one of its seven solvent accessible lysines $(8,9)$. It is worth noting that "head to tail" linked linear polyubiquitin chains, in which ubiquitin is linked via its $\mathrm{N}$-terminal methionine were recently characterized; this unique linkage has been reviewed elsewhere (17).

Polyubiquitin chains linked via different lysines have distinct macromolecular structures. These distinct macromolecular structures are recognized by ubiquitin-binding proteins specific for certain polyubiquitin structures; these ubiquitin binding proteins ultimately direct distinct downstream protein fates. For example, K63 chains can provide a scaffold for protein complex formation. By contrast, "canonical” K48 chains are recruited to the proteasome, and thus promote degradation. However, distinct chains can target a protein for the same fate: all "atypical" ubiquitin linkages except K63 (e.g., lysine 6, 11, 27, 29, or 33) are recognized by proteasomal ubiquitin-binding domain proteins (18). The purpose of this redundancy is as yet unknown, and it is further complicated by the fact that more complex, branched chains of mixed linkages (heterotypic chains) also occur, although few downstream effects of these mixed linkages have been determined in cells $(9,19)$.

Ubiquitylation involves formation of covalent bonds; however, as with other post-translational modifications, ubiquitylation is reversible. Ubiquitin can be removed from proteins by deubiquitylating enzymes (DUBs), which can be specific for certain types of ubiquitin linkages and/or ubiquitylated protein substrates $(12,20)$. DUB activity is also required to generate a pool of free ubiquitin monomers from ubiquitin precursors, establishing these enzymes as key to initiating the ubiquitylation cascade (21). Thus, ubiquitylation is a highly dynamic, complex, and controlled form of molecular regulation, and a form of post-translational modification that impacts almost all proteins in the cell. To deal with such a vast array of possible targets, the substrate-specific components of the ubiquitylation cascade - E3 ligases and DUBs - show extensive diversity, while E1 and E2 enzymes are highly conserved and limited in number. Putative and verified ubiquitin enzymes in the mammalian genome are predicted to number more than 700 (12).

Our understanding of how ubiquitylation modulates TCR signaling is still in its infancy. Genetic loss-of-function studies are beginning to reveal some of the key enzymes and accessory proteins involved. Based on these studies, we now know that E3 ligases and DUBs affect many steps within the signaling cascades downstream of the TCR that culminate in the activation of critical transcription factors, such as NF- $\kappa \mathrm{B}, \mathrm{NFAT}$, and AP-1. Several E3 ligases have been shown to be key players in the induction of anergy and in the differentiation of T helper cell subsets (10). However, for most E3 ligases and DUBs with described roles in the immune system, the specific substrates that regulate the impacted signaling pathways have yet to be identified. Indeed, for many E3 ubiquitin ligases and DUBs, whether substrate binding or enzymatic function is required for their observed function in $\mathrm{T}$ cells has yet to be directly tested.

The studies done to date identifying substrates and roles for E3 ligases and DUBs in T cells have uniformly been targeted in nature, based on use of genetic loss-of-function mouse or cell models. This approach has characterized many critical ubiquitylation events in activated T cells. However, these targeted studies are inherently limited in scope and fail to integrate previously described ubiquitylation events downstream of the TCR with newly defined ubiquitylation substrates. Thus, more global profiling of ubiquitylation events is needed to validate previous findings and uncover new roles for ubiquitylation in $\mathrm{T}$ cells in a high-throughput manner, enabling more targeted future studies. In this regard, ubiquitylation studies in immune cells lag behind phosphorylation studies. Global phosphoproteome studies have characterized dynamic phosphorylation events that occur during engagement of the TCR and co-stimulatory molecules (22-28). Similar studies have yet to be done for ubiquitylation in T cells. New quantitative proteomics platforms have recently been developed that have the potential to identify ubiquitylation events critical for $T$ cell function, validate previous mechanistic findings, and reveal relationships between ubiquitylation and protein fate in a more global fashion.

In this review, we have focused on families of E3 ligases and DUBs that are known to regulate TCR signaling. The paucity of mechanistic information demonstrates the need for new tools, techniques, and further research to reveal how ubiquitylation regulates substrate fate and function and how this impacts TCR signaling events. To this end, we discuss the potential and practical limitations of new proteomic approaches to probe the ubiquitylome of $\mathrm{T}$ cells, and thus aid in unbiased screening of substrates.

\section{E3 Ubiquitin Ligases}

E3 ubiquitin ligases have one common feature - the ability to select the protein substrates in the cell that will be covalently "tagged" with ubiquitin, thereby imparting substrate specificity to the ubiquitin cascade. Each E3 contains one or more domains that allow substrate binding, as well as a domain that binds an ubiquitin-conjugated E2. In the case of the HECT-type E3 ubiquitin ligases, E2 binding occurs within the HECT domain, while among RING type ligases E2 binding occurs via the RING domain. Currently, there are only a few catalytic HECT-type ligases with known functions in T cells - all of these are members of the neuronal precursor cell expressed and developmentally down-regulated protein 4 (Nedd4) family discussed below. All other E3 ubiquitin ligases with known roles in TCR signaling are non-catalytic, RING-type ligases. In Table 1, we have categorized several well-known E3 ubiquitin ligases, described in more detail

\begin{tabular}{llll}
\hline \multicolumn{2}{l}{ TABLE 1 | E3 ligase } & can promote or inhibit activation of T cells. \\
\hline $\begin{array}{l}\text { Promotes T cell } \\
\text { activation and } \\
\text { proliferation }\end{array}$ & $\begin{array}{l}\text { Limits T cell } \\
\text { activation }\end{array}$ & $\begin{array}{l}\text { Ties T cell } \\
\text { activation to } \\
\text { co-stimulation }\end{array}$ & $\begin{array}{l}\text { Induces T } \\
\text { cell anergy }\end{array}$ \\
\hline Nedd4 & & TRIM30 & GRAlL \\
WWP2 & Itch & TRAF6 & Cbl-b \\
TRIM28 & Nedd4-2 & Cbl-b & Itch \\
Cul1 & TRIM27 & Itch & \\
Stub1 & Peli1 & & \\
TRAF6 & Cbl-b & & \\
TRAF2 & (c-Cbl) & &
\end{tabular}


below, based on the role of the ligase in promoting/preventing $\mathrm{T}$ cell activation.

\section{CASITAS B-LINEAGE LYMPHOMA LIGASES}

The three highly homologous casitas B-lineage lymphoma ( $\mathrm{Cbl})$ proteins, $\mathrm{Cbl}$ (c-Cbl, Cbl2, or RNF55), Cbl-b (also termed RNF56), and Cbl-c/Cbl-3 (also termed Cbl-SL or RNF57), have a RING domain, which allows interactions with E2 conjugating enzymes $(31,32)$, and multiple protein-protein interaction domains to facilitate their selection of substrates $(33,34)$. These proteinprotein interaction regions include a tyrosine kinase-binding domain (TKB), a Src homology (SH2) domain, a proline-rich motif, an ubiquitin-associated (UBA) domain, and additional motifs known to be phosphorylated in a signal-dependent manner. $\mathrm{Cbl}-\mathrm{b}$ and $\mathrm{c}-\mathrm{Cbl}$ were among the first $\mathrm{E} 3$ ubiquitin ligases implicated in TCR signaling $(29,30)$. The third family member, $\mathrm{Cbl}-\mathrm{c}$, is not known to be expressed in T cells. Their diversity of interaction motifs make Cbl-b and c-Cbl particularly well suited for binding mediators of signaling cascades, such as those downstream of the TCR.

$\mathrm{Cbl}-\mathrm{b}$ negatively regulates $\mathrm{T}$ cell activation. Mice lacking Cbl-b spontaneously develop autoimmune disease as they age and are more susceptible to induced forms of autoimmune disease. This is not due to a defect in the thymic selection of Cbl-b deficient $\mathrm{T}$ cells, as Cbl-b is predominantly expressed in T cells only after they have completed thymic development (35). Rather, T cells lacking Cbl-b can become fully activated in the absence of CD28 co-stimulation $(29,30,36)$. Additionally, in vitro Cbl-b deficient $\mathrm{CD} 4^{+} \mathrm{T}$ cells show increased IL-2 production and proliferation in response to TCR/co-stimulation $(29,30)$. In peripheral T cells, TCR engagement drives activation of NFAT, which in turn leads to Cbl-b expression (37). Once expressed, Cbl-b has been proposed to mediate ubiquitylation of multiple TCR signaling mediators, including PLC- $\gamma$, the PI3 kinase subunit p85, and PKC $(29,30,37-40)$. However, whether these are the relevant substrates remains somewhat controversial (41), and the precise means through which Cbl-b regulates TCR signaling via these and other substrates remains to be defined.

c-Cbl, like Cbl-b, negatively regulates TCR signaling. Unlike $\mathrm{Cbl}-\mathrm{b}, \mathrm{c}-\mathrm{Cbl}$ is expressed predominantly in the thymus where it regulates levels of the TCR and signal strength upon receptor ligation. T cells lacking c-Cbl have enhanced Zap-70 phosphorylation, elevated TCR levels, and altered thymic selection $(42,43)$. Following TCR ligation, Zap-70 recruits c-Cbl to ubiquitylate the TCR $\zeta$ chain (44). Interestingly, Zap-70-deficient thymocytes do not show defects in TCR surface expression $(45,46)$, supporting that other molecules, such as SLAP, may help recruit c-Cbl to the TCR complex (47-51). Once ubiquitylated, the TCR is degraded within lysosomes, as degradation is blocked by the use of lysosomal inhibitors (51) or deficiency in lysosomal-associated proteins, such as LAPTM5 $(52,53)$. Although c-Cbl has been shown to ubiquitylate other substrates, such as WASP (54), p85 (55), and CD5 (56), the relevance of ubiquitylation of these substrates in TCR signal modulation is less well-defined.
The similar yet non-redundant role of $\mathrm{c}-\mathrm{Cbl}$ and Cbl-b in T cells is emphasized by the exacerbated phenotype of mice with doubly deficient $\mathrm{T}$ cells (57). Conditional deletion of both c-Cbl and Cbl-b in T cells leads to robust $\mathrm{T}$ cell-mediated inflammation mice: doubly deficient $\mathrm{CD} 4^{+} \mathrm{T}$ cells show defective surface TCR downregulation after ligand engagement, leading to prolonged signaling and $\mathrm{T}$ cell hyperesponsiveness (57).

More recently, Cbl-b has been described to work with other E3 ligases. Cbl-b can bind to the prototypic member of the Nedd4family of E3 ubiquitin ligases, Nedd4 $(58,59)$. Nedd4 and Cbl-b have been shown to regulate each other's function, either through degradation or by recruitment of the ligase to other factors (58, 59). Additionally, as described below, Cbl-b can work with STIP1 homology and U-box containing protein 1 (Stub1) to ubiquitylate FoxP3 (58-60).

\section{NEURONAL PRECURSOR CELL EXPRESSED AND DEVELOPMENTALLY DOWN-REGULATED PROTEIN 4 LIGASES}

The neuronal precursor cell expressed and developmentally down-regulated protein 4 (Nedd4) family of catalytic HECT type E3 ubiquitin ligases is highly conserved, with an ortholog in budding yeast (61). These catalytic E3 ubiquitin ligases serve double duty in the ubiquitin cascade - providing both substrate specificity and catalyzing the final transfer of ubiquitin to accessible lysines on the target protein. As with other catalytic E3 ubiquitin ligases, Nedd4-family members are regulated by autoinhibition and activated by phosphorylation or through interactions with accessory proteins (62). The nine Nedd4-family proteins expressed in mammals share a modular architecture consisting of two to four WW domains that facilitate protein-protein interactions, a lipid and calcium-binding C2 domain, and the catalytic HECT domain. These nine Nedd4-family members constitute $\sim 1 / 3$ of the known HECT type E3 ligases in mice and humans $(14,63)$. Of the nine family members, evidence exists in the literature for expression of four of these in T cells: Nedd4, Nedd4-2 (or Nedd4L), WWP2, and Itch. The similarity of the Nedd4 family members has made mechanistic studies particularly challenging. In many cases, substrates identified for one family member are capable of being ubiquitylated by most other family members in vitro. Thus, while certain substrates have been described as being shared or context specific, cases of mistaken identity have also occurred $(37,62)$.

Nedd 4 the archetypal family member, was originally characterized, along with the highly homologous Nedd4-2, as a negative regulator of epithelial sodium channel (ENAC) expression (64-67). Follow-up studies revealed numerous other shared, as well as unique, substrates for these E3s, including other ion channel and growth factor receptors (63). These substrates have not been specifically investigated in $\mathrm{T}$ cells, despite clear relevance for many of these proteins in T cell survival and TCR signaling. In the case of Nedd4, homozygous deletion resulted in embryonic lethality, and no T cell-specific knockout has been made; therefore, studies of Nedd 4 function in T cells have been limited. Using fetal liver chimeras, Yang et al. found that Nedd4 promotes TCR 
signaling via degradation of Cbl-b (59). Due to accumulation of Cbl-b, T cells lacking Nedd4 were hypo-responsive to stimuli. An additional substrate of Nedd4, and perhaps WWP2 and Nedd4-2 as well $(63,68,69)$, PTEN is also thought to have a role in $\mathrm{Nedd4}^{-/-} \mathrm{T}$ cell hyporesponsiveness. Guo et al. proposed that, in the absence of Cbl-b, Nedd4 promotes PTEN inactivation via degradation, leading in part to the hyper-responsive phenotype of Cbl- $b^{-/-} \mathrm{T}$ cells (70). There is some evidence that Nedd4 can also act as a negative regulator of $\mathrm{T}$ cell responses, as, together with Itch, Nedd 4 was proposed to degrade Bcl10 in order to limit NF- $\kappa \mathrm{B}$ responses after TCR stimulation (71).

A thorough characterization of the role for Nedd4-2 in T cells is also lacking, as knockout mice show lethality at 3 weeks of age (72) and no T cell-specific knockout mouse has been made. In $\mathrm{CD}^{+} \mathrm{T}$ cells, however, Nedd4-2 was recently published to degrade JunB, a transcription factor previously published as a substrate of the Nedd4-family member Itch (73). However, this remains to be validated and described in more detail.

WWP2 is a much less studied family member, and to date no phenotype for knockout animals has been published. Using exogenous over-expression in T cells, one study identified WWP2 as a positive regulator of $\mathrm{T}$ cell activation, similar to Nedd4, as WWP2 was found to degrade Egr2, thereby limiting activation-induced cell death (74). The finding that PTEN can be degraded by WWP2 in certain transformed cell lines (69) suggests that WWP2 could regulate PTEN levels and/or function during $\mathrm{T}$ cell activation, although this has not been investigated.

Of the Nedd 4 family members, Itch is the best studied in immune cells due to the striking immunological phenotype of Itchy mutant mice, which develop fulminant auto-inflammatory disease, characterized by Th2 skewing of $\mathrm{CD}^{+} \mathrm{T}$ cells $(75,76)$. Along with gene related to anergy in lymphocyte (GRAIL) and Cbl-b, Itch is considered to be a tolerogenic E3 ligase with important functions in restraining inappropriate immune responses. In activated $\mathrm{T}$ cells, Itch has been proposed to degrade PKC $\theta$ and PLC $\gamma 1$ (37). In mouse peripheral T cells, one well-characterized substrate of Itch is JunB, an IL-4 transcription factor that accumulates in the absence of Itch, contributing to the $\mathrm{T}_{\mathrm{H}} 2$-type inflammation in Itchy mice $(76,77)$. However, over-expression of JunB only partially recapitulates the Itchy mouse phenotype, suggesting that other factors are also targets of Itch E3 ligase activity. Prior to the description of Itch as an E3 ligase for JunB, Itch was shown biochemically to degrade Notch. This may explain why Itchy mutant hematopoietic stem cells display increased proliferation and longterm self-renewing properties characterized by increased Notch1 signaling (78-81). FoxO1 was recently described as a target of Itch in vaccinia responsive $\mathrm{T}_{\mathrm{FH}}$, but how FoxO1 is regulated in other $\mathrm{T}$ cell compartments has yet to be addressed (82). Itch also has direct relevance to human disease, as humans with mutations in Itch also show immunological defects (83). However, the molecular mechanisms within human immune cells leading to aberrant immune responses have not been described.

\section{TRIPARTITE MOTIF LIGASES}

Tripartite motif protein (TRIM) E3 ligases are named for the presence of the tripartite motif, which contains a RING domain, one or two B-Box domains, and a coiled coil domain (84). This unique motif is invariably located at the $\mathrm{N}$ terminus, while there is broad heterogeneity in the C-terminal domains (85). TRIMs interact to generate homotypic and heterotypic multimers, forming discrete macromolecular structures in specific cellular compartments $(84,86,87)$. TRIMs are a large, heterogeneous family in mammals, with $\sim 70$ proteins in both mice and humans. Analysis of the C-terminal domains suggests that TRIMs have diversified extensively in vertebrates, perhaps in response to pathogens (88, 89). The E3 ligase function of TRIMs is not limited to ubiquitin - although TRIMs can promote ubiquitylation through their interaction with E2 ubiquitin conjugating enzymes, TRIM RING domains can also mediate sumoylation and ISGylation with a variety of other E2s (90-92). Much work has focused on a role for TRIMs in pathogen responses, particularly in promoting antiviral responses in innate immune cells (93-103). This literature has been the subject of several reviews (104-107). However, little is known about the role of TRIMs in adaptive immune cells.

The most well-characterized TRIM in CD4 ${ }^{+} \mathrm{T}$ cells is TRIM28 (also called KAP/TIF1 $\alpha$ ), which contains histone interacting domains in addition to the tripartite motif, and is inducibly phosphorylated during TCR signaling (108). TRIM $28^{\mathrm{fl} / \mathrm{fl}}$ $\mathrm{CD} 4 \mathrm{Cre}^{+}$mice have defective TCR $\alpha$ rearrangement and reduced peripheral T cell numbers; these TRIM28-deficient T cells have impaired cell proliferation and IL2 production (108, 109). Somewhat surprisingly, however, these mice develop autoimmune disease, characterized by high percentages of $\mathrm{T}_{\mathrm{H}} 17$ cells and defective Tregs (108).

Several other TRIM family members have known or suggested roles in $\mathrm{CD}^{+} \mathrm{T}$ cells. TRIM27 is a negative regulator of $\mathrm{CD}^{+}$ $\mathrm{T}$ cell activation by promoting degradation of PI3KC2 $\beta$, thereby limiting calcium release and preventing a sustained calcium signal after TCR engagement (110). Similarly, TRIM30 also appears to negatively regulate TCR signals, as $\mathrm{CD} 4^{+} \mathrm{T}$ cells from TRIM $30^{-/-}$mice show a loss of co-stimulatory molecule dependence and increased homeostatic proliferation upon transfer into Rag1 $^{-1-}$ recipients (111). Within innate cells, TRIM21 promotes ubiquitylation of IRF3, IRF7, and IRF8, with either pro- or antiinflammatory effects on cytokine production (112-114). One study of TRIM $21^{-1-}$ mice determined that several dysregulated cytokines are related to $\mathrm{T}_{\mathrm{H}} 17$ development (115); however, whether this is due to $\mathrm{T}$ cell intrinsic hyper-cytokine production remains to be seen. While many TRIMs have particularly high expression in innate cells, some are preferentially expressed within $\mathrm{CD}^{+}{ }^{+} \mathrm{T}$ cells at the RNA level, including TRIM1, TRIM9, TRIM18, and TRIM46 (116). To date, no findings on these TRIMs in $\mathrm{T}$ cells have been published.

\section{CULLIN RING LIGASES}

The cullin RING ligases (CRLs) are the largest known family of E3 ligases. Translational research on cullins has primarily focused on their potential role in cancer because they are known to affect genes involved in cell cycle progression, cell proliferation, apoptosis, and DNA repair (117). Despite the relevance of these processes to $\mathrm{T}$ cell function, minimal work has been done on cullins in immune cells. Cullin proteins themselves do not 
possess an E3 ligase domain or function. Rather, cullins are the central scaffold of CRL complexes. CRLs are composed of cullin scaffold, a RING-box protein, a substrate recognition protein, and, in most cases, an adapter protein linking the cullin to the substrate recognition protein. There are 8 cullin family members, but there are over 200 CRLs due to the modular nature of these complexes $(118,119)$. The RING-box protein, Rbx1 or Rbx2, binds to the globular C-terminal domain (CTD) of the cullin and promotes CRL enzymatic activity by interaction with an E2 conjugating enzyme. The cullin CTD also contains a conserved lysine that must be NEDDylated in order for the cullin to be in its active form (117). Within the cullin N-terminal domain (NTD), cullin repeats either bind directly to a substrate-binding protein or indirectly via an adapter protein $(119,120)$. Assembly and structure of CRL complexes have been studied extensively and have been reviewed elsewhere (121).

The most well-studied member of the cullin family is CUL1. CUL1 expression in human tissues is highest in the spleen, blood, and tonsils, suggesting a possible immune function (122). CUL1 CRLs, also known as SCF complexes, are a complex of the adaptor Skp1, Rbx1, and 1 of nearly 70 different F-box proteins. The substrate specificity of the SCF complex is thought to be determined by the F-box protein (118). Of these 70 CUL1 CRLs, only 3 have been fully characterized in terms of substrate and function $(118,123)$. Substrates of the SCF are within known TCR signaling pathways and include the IFN $\alpha$ receptor 1 and $\mathrm{I} \kappa \mathrm{B} \alpha(122$, 124-126). However, only one study has specifically looked at the role of CUL1 in TCR signaling. In this study, TCR stimulation led to the ubiquitylation of $\mathrm{p} 27^{\mathrm{kip} 1}$ by SCF ${ }^{\mathrm{skp} 2} \cdot \mathrm{p} 27^{\mathrm{kip} 1}$ ubiquitylation and subsequent degradation allowed $\mathrm{T}$ cells to proceed into $\mathrm{S}$ phase. TCR stimulation increases expression of Skp2, the F-box protein that targets the ligase activity of SCF to $\mathrm{p} 27^{\mathrm{kip} 1}$, in contrast transcription of CUL1 and Skp1 was not affected (127).

Two other cullins have known roles in T cells, although their function in TCR signaling is unclear. Recently, it was shown that knockdown of CUL2 and CUL3 in a T cell line led to a robust increase in IL-2 production following TCR stimulation (10). CUL3 is the only member of the cullin family for which a T-cell-specific knockout mouse exists. Ratios of thymic CD4 ${ }^{+}$ and $\mathrm{CD}^{+} \mathrm{T}$ cells are normal in these mice, but specific effector cell populations are disrupted. Levels of $\mathrm{T}_{\mathrm{FH}}$ cells are abnormally high and NKT cells are significantly reduced in number (128). CUL3 associates with the BTB-ZF family of transcription factors to make epigenetic changes that direct the differentiation of these two T cell populations. CUL3 leads to the promotion of the NKT cell lineage and the inhibition of $\mathrm{T}_{\mathrm{FH}}$ cells by associating with PLZF and Bcl6, respectively $(128,129)$. This phenotype was shown to be independent of TCR signaling (129), so it remains unclear whether and how CUL3 regulation of TCR signaling regulates $\mathrm{T}$ cell biology.

Perhaps due to the relevance of cullins in cancer, several unbiased proteomic screens have been developed in cell lines and successfully used to identify CRL substrates bound by different F-box proteins. These screens have utilized substratetrapping mutations in the F-box proteins that prevent release of the ubiquitylated substrate, tagged versions of F-box proteins for specific immunoprecipitation, and the chemical inhibitor of the
Nedd8-activating enzyme to prevent cullin activation (130-133). These large scale studies have achieved good specificity and reproducibility; however, utility of these published work flows is likely limited in primary immune cells due to the requirement for numerous replicates and a transfectable cell type.

\section{GENE RELATED TO ANERGY IN LYMPHOCYTES}

As indicated by its name, gene related to anergy in lymphocytes (GRAIL) is a RING-type E3 ubiquitin ligase that is crucial for the induction of anergy in $\mathrm{T}$ cells. Resting $\mathrm{T}$ cells generally express low levels of GRAIL; these levels are further decreased following TCR/CD28 stimulation (134). Conversely, expression of GRAIL is rapidly increased following anergic stimulation of T cells. Resting $\mathrm{T}$ cells that over-express GRAIL produce greatly reduced IL-2 in response to TCR stimulation - this reduced IL-2 production depends on GRAIL E3 ligase activity (135). GRAIL over-expressing Jurkat and DO11.10 T cells exhibit impaired actin polarization at the immunological synapse following TCR stimulation, and also demonstrate impaired lymphocyte function-associated antigen (LFA) polarization and JNK phosphorylation downstream of TCR stimulation (136).

GRAIL knockout BALB/c mice have normal numbers and ratios of lymphocytes. However, established methods of inducing oral tolerance in these mice are ineffective (137). Aged GRAIL knockout mice develop autoimmune disease with infiltration of lymphocytes in their lungs and kidneys (138). CD4 ${ }^{+} \mathrm{T}$ cells from GRAIL knockout mice are more sensitive to TCR stimulation, exhibiting hyperproliferation and increased production of IL-2 and IFN- $\gamma$ (137). The CD3 $\zeta$ chains have been implicated as a possible target of GRAIL's E3 ligase activity. Following stimulation with $\alpha \mathrm{CD} 3$ alone, there are fewer TCRs on the cell surface and a concordant increase in ubiquitylation of $\mathrm{CD} 3 \zeta$; in the absence of GRAIL, this downregulation of the TCR does not occur (138).

\section{PELLINO 1}

The three Pellino family members are highly homologous, and all contain a RING domain that is critical to their function. In T cells, Pellino 1 (Peli1) acts as a negative regulator of $\mathrm{T}$ cell activation via its interaction with the NF- $\kappa$ B pathway. Cells deficient in Peli1 are hyper-responsive following TCR stimulation, with increased production of IL- 2 and IFN- $\gamma$. These cells are also resistant to TGF- $\beta$-or Treg-mediated suppression (139). The hyper-responsive phenotype of Peli1 knockout cells correlates with increased protein levels of NF- $\kappa \mathrm{B}$ and increased nuclear c-Rel following TCR stimulation. Peli1 has been shown to ubiquitylate c-Rel, forming K48 chains that initiate its degradation (139). Peli1 knockout mice have increased numbers of memory $\mathrm{T}$ cells in both the spleen and lymph nodes. Similar changes in $\mathrm{T}$ cell populations are seen among Peli-deficient $\mathrm{T}$ cells in mixed bone marrow chimeras, indicating that Peli1 acts intrinsically on these T cell populations. Aged Peli1 mice develop autoimmune disease with anti-nuclear antibodies in the serum, immune complexes in the kidneys, and lymphocyte infiltrates in the kidneys, liver, and lungs (139). 


\section{STIP1 HOMOLOGY AND U-BOX CONTAINING PROTEIN 1}

The U-box E3 ubiquitin ligase Stub1, also known as carboxy terminus of HSP70-interacting protein (CHIP) plays an important role as a "co-chaperone," associating with protein folding machinery to promote degradation of aberrantly folded proteins during new protein synthesis. Consistent with this role, Stub1 is highly expressed in metabolically active cells and tissues, in which a high level of translation is maintained $(140,141)$. In T cells, Stub1 has been shown to regulate NF- $\kappa$ B activation following TCR ligation, suggesting a role in tuning $\mathrm{T}$ cell activation. Stub 1 also limits the levels of FoxP3 after TCR stimulation, supporting a role in Treg cell fate.

Specifically, Stub1 is thought to amplify NF- $\kappa \mathrm{B}$ signaling through ubiquitylation of CARMA1. Jurkat T cells with Stub1 knocked-down via RNAi show decreased phosphorylation of I $\mathrm{B} \alpha$, decreased ubiquitylation of CARMA1, and decreased transcription of IL-2 in vitro (142). Following TCR ligation of regulatory T cells, Stub1 has been shown to ubiquitylate FoxP3. In Jurkat $\mathrm{T}$ cells constitutively expressing FoxP3, degradation of FoxP3 following TCR and inflammatory cytokine signaling depends on Stub1 ubiquitylation of FoxP3. Accordingly, knockdown of Stub1 led to the accumulation of FoxP3 in this cell line (143). Stub1 also associates with FoxP3 upon TCR stimulation. Both Stub1 and Cbl-b can ubiquitylate FoxP3 following TCR stimulation, but Stub1 may play a more dominant role as T cells deficient in Cbl-b show reduced ubiquitylation, whereas $\mathrm{T}$ cells deficient in Stub1 have a complete lack of FoxP3 ubiquitylation (60). Much of the work thus far on Stub1 has been performed using cell lines or over-expression systems. Given that Stub1 $1^{-/-}$ mice develop spontaneous atopic lung inflammation (144), while it remains unclear whether or how these mechanisms regulate $\mathrm{T}$ cell function in vivo, an intrinsic role for Stub1 in regulation of activated $\mathrm{T}$ cells seems likely.

While many E3 ligases and DUBs operate as part of cellular quality control mechanisms, as is the case for Stub1, few also have specific, separable roles in signal responses. Thus, it will be interesting to see if future research identifies the Stub1 targets described thus far as client proteins of molecular chaperones.

\section{TNF RECEPTOR-ASSOCIATED FACTOR FAMILY}

TNF receptor-associated factor (TRAF) proteins are defined by their association with membrane-bound receptors in the tumor necrosis factor receptor (TNFR) family. All TRAF proteins have a conserved TRAF domain at their C-terminus that interacts both with these associated membrane receptors and with other TRAF proteins to form hetero- and homodimers. All TRAF proteins except TRAF1 have an N-terminal RING domain (145). TRAF proteins facilitate K63 polyubiquitylation of their substrates, and thus promote protein-protein interactions as opposed to targeting the substrate for proteasomal degradation (146).
While multiple TRAF E3 ligases are expressed in T cells, the most well-characterized in regards to TCR signaling is TRAF6. TRAF6 is required for NF- $\kappa \mathrm{B}$ pathway activation following TCR stimulation. Knockdown of TRAF6 in Jurkat T cells greatly reduces NF- $\kappa \mathrm{B}$ activation, likely due to loss of $\mathrm{I} \kappa \mathrm{B} \alpha$ phosphorylation. TRAF6 can ubiquitylate MALT1 oligomers via K63 linkages that promote protein-protein interactions (147). The ubiquitylation of MALT1 leads to the recruitment of NEMO/IKK $\gamma$ to the CARMA1-MALT1-BCL10 (CMB) complex (148) where it is phosphorylated. TRAF6 also ubiquitylates NEMO (147) and recruits Caspase8 to lipid rafts. All of these steps are required for effective NF- $\kappa B$ signaling in T cells following TCR ligation (149). Somewhat surprisingly, although TRAF6 activates NF- $\kappa B$ in vitro, the primary phenotype of T cell-specific TRAF6 knockout mice is systemic autoimmune disease and a failure to induce anergy (150, 151). T cells from these mice are resistant to suppression by Treg cells and do not require CD28 co-stimulation for their activation. These cells also have constitutively activated Akt and enhanced phosphorylation of p85 following TCR stimulation (even without co-stimulation). This hyperactivation of PI3K pathway components may be responsible for the resistance to anergy in TRAF6deficient T cells (150). Additionally, TRAF6-deficient T cells have reduced Cbl-b expression following anergizing conditions (151). Although the specific connection between TRAF6 and Cbl-b remains unknown, dysregulation of Cbl-b could also contribute to the loss of anergy in TRAF6-deficient T cells.

TRAF2 is also involved in the activation of the NF- $\kappa B$ pathway in $\mathrm{T}$ cells, but the underlying mechanism is poorly understood. TRAF2 acts on the non-canonical NF- $\kappa$ B pathway through a signaling complex termed the OX40 signalosome. TCR and OX40 signaling leads to an association between OX40 and protein kinase $\mathrm{B}(\mathrm{PKB})$, and $\mathrm{PKB}$ activation. This association is reduced in TRAF2-knockdown T cells, resulting in decreased PKB activation and reduced IL-2 expression (152), suggesting that TRAF2 ubiquitylation plays an activating role in formation of the OX40 signalsome. The OX40 signalosome can also activate the CMB complex leading to NF- $\kappa \mathrm{B}$ activation. TRAF2-knockdown T cells fail to fully activate NF- $\kappa \mathrm{B}$ likely due to defective formation of the signalosome complex (153).

Genetic loss-of-function studies for other TRAFs hint toward a role in $\mathrm{T}$ cell function, but mechanisms are broadly lacking. For example, TRAF1-deficient mice have increased numbers of lymphocytes in peripheral lymphoid compartments and an increased $\mathrm{T} / \mathrm{B}$ cell ratio. $\mathrm{T}$ cells from these mice are hyper-proliferative in response to TCR stimulation, and/or when stimulated with IL-2 (154). By contrast, T cell-specific TRAF3 knockout mice show normal numbers of total $\mathrm{T}$ cells but increased numbers of Treg cells and $\mathrm{CD}^{+}$effector/memory $\mathrm{T}$ cells, with reduced numbers of $\mathrm{CD}^{+} \mathrm{T}$ cells $(155,156)$. In vitro, $\mathrm{CD} 4^{+} \mathrm{T}$ cells from these mice showed reduced phosphorylation of ERK, LAT, PLC $\gamma 1$, and ZAP70, and reduced proliferation and cytokine production in response to TCR stimulation (155). This is quite different from what is seen in TRAF5 knockout mice. These mice show no obvious phenotype or immune deficiency, but when challenged using a model of airways hypersensitivity, they show increased $\mathrm{T}_{\mathrm{H}} 2$ lung inflammation compared to WT mice. In vitro, $\mathrm{T}$ cells 
from these mice preferentially differentiate into $\mathrm{T}_{\mathrm{H}} 2$ cells following activation of TCR/OX40 signaling (157).

\section{Deubiquitylating Enzymes}

The deubiquitylating enzymes (DUBs) are a class of proteases that cleave ubiquitin from its target protein, thus allowing ubiquitylation to be a reversible process. At this time, 95 putative DUB genes have been reported within the human genome based on having one of the five ubiquitin-specific protease domains: ubiquitin-specific protease (USP), ubiquitin C-terminal hydrolase (UCH), ovarian tumor (OTU), Machado-Josephin (MJD), or JAB1/MPN/Mov34 metalloenzyme (JAMM) (158). These five domains define the five subclasses of DUBs. Most DUBs act as cysteine proteases, relying on a cysteine followed by a histidine in the catalytic site. The histidine allows for the deprotonation of the cysteine residue, which then cleaves the C-terminus of ubiquitin by nucleophilic attack $(20,158)$. The substrate of a DUB can be a specific ubiquitin polymer or a specific target protein, but targets (substrates) for most DUBs are currently unknown. Mass spectrometry of epitope-tagged proteins has identified factors that interact with DUBs and have elucidated potential roles for DUBs in specific biological processes, many of which are relevant in T cells (159).

\section{UBIQUITIN-SPECIFIC PROTEASES}

Ubiquitin-specific proteases (USPs) are one of the main families of cysteine proteases, and the largest family of DUBs. Since cleavage occurs between two ubiquitins within a polyubiquitin chain, most USPs contain at least two ubiquitin-binding sites, one for the distal ubiquitin and the other for the proximal ubiquitin (160). Several USP family DUBs have been shown to regulate TCR signaling, including USP9x, USP15, and USP7.

Usp9x is highly expressed in the spleen and thymus of mice (161-163), indicating a possible function in T cells. T cells from chimeric mice with shRNA knockdown of Usp9x demonstrate defective proliferation and reduced IFN- $\gamma$, IL-2, IL-4, and IL-17 production, indicating an inhibition of helper $\mathrm{T}$ cell differentiation or cytokine production (162). This inhibition seems to be due to a decrease in NF- $\kappa \mathrm{B}$ activation following TCR stimulation in Usp9x knockdown T cells. Jurkat T cells with Usp9x knockdown show decreased phosphorylation of I $\mathrm{B} \alpha$, decreased nuclear p65, decreased Bcl10 interaction with CARMA1, and increased ubiquitylation of Bcl10 (162). Thus, Usp9x may be acting on the NF- $\kappa B$ pathway via deubiquitylation of Bcl10. Specifically, Usp9x appears to deubiquitylate K48 ubiquitin linkages on $\mathrm{Bcl} 10$ following TCR stimulation (162). Experiments in mice with a conditional knockout of Usp9x in T cells contradict this finding. Although $\mathrm{T}$ cells lacking Usp9x have diminished proliferation following TCR stimulation, they show no decrease in nuclear translocation of p65 or in the interaction between Bcl10 and Carmal (163). Instead, there is a decrease in phosphorylated LAT and PLC- $\gamma 1$ following TCR stimulation. Mice lacking Usp9x in $\mathrm{T}$ cells ultimately develop a lupus-like autoimmune disease with splenomegaly and anti-nuclear antibodies (163). Usp9x has been shown to deubiquitylate Itch, protecting Itch from degradation in the proteasome after auto-ubiquitylation. Thus, increased degradation of Itch in the absence of USP9x could provide an alternative explanation for the increased autoimmunity in Usp9xdeficient mice. However, the experiments examining Itch have been carried out in vitro in HEK-293T cells and COS-7 cells, not in T cells (161).

Recently, two additional USP DUBs have been published as having roles in T cells. USP15 is abundantly expressed in T cells, and $\mathrm{T}$ cells lacking this enzyme show increased IL-2 and IFN $\gamma$ production. USP15 deubiquitylates MDM2, an E3 ligase that ubiquitylates and degrades P53 as well as NFATc2. In the absence of USP15, MDM2 levels are decreased and NFATc2 levels in the nucleus consequently increase, likely accounting for elevated IL-2 and IFN $\gamma$ production (164). Increased T cell responsiveness led to improved pathogen clearance as well as reduced tumor-induced lethality (164). USP7 decreased immune activation by binding to and stabilizing FoxP3 in regulatory $\mathrm{T}$ cells, perhaps serving to counteract the actions of Stub1 and Cbl-b, which can promote FoxP3 ubiquitylation (143, 165). Though USP7 and Stub1/ Cbl-b have not been investigated together, this post-translation regulation of FoxP3 may be an example of ubiquitin editing. Undoubtedly, future work will uncover additional USP family members that play important roles in modulating TCR signaling and responsiveness.

\section{Ubiquitin Editing}

The relationship between E3 ligases and DUBs parallels that of kinases and phosphatases. The antagonistic functions of E3 ligase and DUBs can quickly create and modify post-translational modifications, and the balance of their functions sets the signaling state of the cell. Ubiquitin, however, is not simply an on/off switch. The fate of the substrate depends not only on the presence or absence of ubiquitin but also on the length and specific linkage type of the attached ubiquitin chain. Ubiquitin itself has seven lysine residues, thus providing seven different locations for linkages in a polyubiquitin chain. The type of ubiquitin chain attached to a substrate dictates the fate of that protein. For example, while a K48-linked chain targets the substrate for proteasomal degradation, a K63-linked chain may recruit other signaling molecules to the substrate. Both E3 ligases and DUBs show preference for forming/removing certain types of ubiquitin linkages. For example, the TRAF E3 ligases (Traf2, 3, and 6) build K63 ubiquitin chains, whereas Usp9x removes K48 ubiquitin chains $(162,166)$. The number and diversity of E3 ligases and DUBs make ubiquitylation an incredibly dynamic post-translational modification. The dynamic alteration of ubiquitin chains is known as ubiquitin editing.

Because the precise substrates of many E3 ligases and DUBs are still unknown, the exact molecular interactions in most instances of ubiquitin editing remain elusive. Ubiquitin editing of NF- $\kappa \mathrm{B}$ is the most well-studied model. The OTU-domain containing DUB, A20, plays a key role in the suppression of the NF- $\mathrm{KB}$ activation and uniquely demonstrates ubiquitin editing by contain both deubiqutylating and E3 ligase domains $(167,168)$. A20 deficient mice die within 3 weeks of birth due to rampant inflammation, likely due to over-activation of NF- $\mathrm{KB}$ (169). Because it contains both DUB and E3 ubiquitin ligase domains, A20 theoretically has the potential to form and edit chains on substrates without 
partnering with other factors. This might be the case in the interaction of A20 with one of its known substrates, the kinase RIP. Downstream of TNF receptor signaling, RIP activity promotes activation of NF- $\kappa \mathrm{B}$; this is terminated by A20. Mechanistically, A20 is thought to facilitate the removal of K63 ubiquitin chains, which promote activity of RIP, and add K48 ubiquitin chains, thus targeting RIP for proteasomal degradation (170).

Most research on A20 has focused on its role in innate immune cells, where its function as an ubiquitin editor is well established. Few studies have focused on the role of A20 in NF- $\kappa B$ signaling following TCR activation. In contrast to innate immune cells, TNF does not induce the expression of A20 in T cells. Instead, A20 is constitutively expressed in mature resting $\mathrm{T}$ cells but is immediately down-regulated following $\mathrm{T}$ cell activation (171, 172). In T cells, TRAF6 and A20 work in functional opposition to edit MALT1 ubiquitylation, thereby keeping NF- $\kappa B$ activation in check downstream of TCR stimulation. TRAF6 promotes K63 ubiquitylation of MALT1, leading to the association of the Carma1-MALT1-Bcl10 (CMB) complex with IKK, subsequent phosphorylation/activation of IKK, and NF- $\kappa B$ activation (148). It has been proposed that A20 facilitates deubiquitylation of MALT1 to limit the CBM-IKK interaction and suppress NF- $\kappa B$ activation (172). Thus, TRAF6 and A20 ubiquitin editing of MALT1 provides a rheostat for T cell activation.

Structure-function studies have recently challenged the direct role of A20 in ubiquitin editing. Specifically, A20's role as a DUB was recently called into question. A knock-in mouse that specifically lacks A20 DUB activity was found to have normal NF- $\kappa \mathrm{B}$ signaling and no overt phenotype (173), suggesting that A20's DUB function is dispensable for normal NF- $\kappa$ B signaling, and its ubiquitin editing function may rely on its other domains (such as its E3 ligase RING domain) or higher complex formation. However, A20 may be required as a DUB in other signaling cascades. Specifically, A20 DUB activity was shown to regulate necroptosis in T cells, as well as in other cell types (174).

Similar to A20, the UCH-type deubiquitylating enzyme CYLD limits NF- $\kappa$ B activation by deubiquitylation. While A20 acts as a negative feedback mechanism to NF- $\kappa \mathrm{B}$ stimulation, CYLD is thought to suppress basal NF- $\kappa \mathrm{B}$ activation. In the absence of any robust stimulation of NF- $\kappa \mathrm{B}$ (such as TCR engagement or cytokine signaling), CYLD deubiquitylates TRAF2, TRAF6, and NEMO, dampening NF- $\mathrm{KB}$ signaling by removing activating K63 chains formed by TRAF2/6 $(175,176)$. Additionally, in both macrophages and T cells, CYLD inhibits the ubiquitylation and subsequent activation of Tak1, a kinase that activates both IKK and JNK $(177,178)$. Therefore, CYLD is a key negative regulator of both the NF- $\kappa \mathrm{B}$ and AP-1 pathways through negative regulation of upstream signaling intermediates.

CYLD and A20 demonstrate how the balance and specificity of ubiquitylation/deubiquitylation can create a dynamic system for modulating immune signaling. In Figure 2, we have summarized the known roles in $\mathrm{T}$ cells for the ligases described here. While limited evidence of ubiquitin editing exists to date in primary $\mathrm{CD}^{+} \mathrm{T}$ cells, the opportunity for interplay and co-regulation of certain substrates by E3 ligases and DUBs during TCR signaling is clear, providing an exciting opportunity for further defining how TCR signals are regulated, which may provide new targets

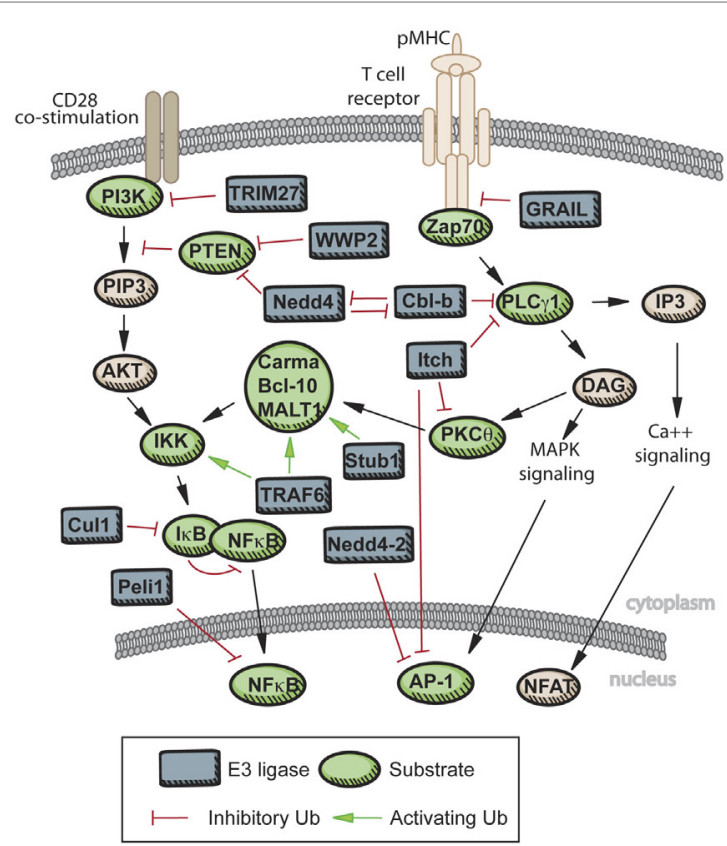

FIGURE 2 | Known roles of E3 ligase and DUBs in TCR signaling. Upon engagement of the TCR with peptide-MHC, several E3 ligases act to limit the strength of TCR signaling. GRAIL, CBL-B, and Itch are active in limiting proximal TCR signaling, and therefore enforcing T cell tolerance. Additional E3 ligases are activated with engagement of co-stimulatory molecules, and these E3s can promote activation of a T cell receiving signals through both the TCR and CD28 (Nedd4, WWP2), or limit signaling downstream of CD28 (TRIM27). Further downstream, activation of NF-кB is dependent on K63 chain formation on a variety of scaffolding proteins, while activity of the AP-1 complex and nuclear localization of NFAT can be inhibited directly by E3 ligase activity or by repression further upstream.

for therapeutic modulation. In this regard, the controversy surrounding A20's DUB function serves as an important warning that domain homology does not necessarily equate with function in all systems, and that detailed structure-function studies should be undertaken prior to attempts at therapeutic targeting. Figure 2 also highlights important aspects of many ubiquitylation studies in T cells: first, that targeted approaches typically yield only one enzyme-substrate relationship and, second, that several well-studied E3 ligases or DUBs have now been published with multiple, in some cases overlapping substrates. Thus, generally lacking from this work is integration of known ubiquitylation events with newly identified events into more cohesive signaling networks.

\section{UNBIASED PROTEOMIC APPROACHES FOR IDENTIFYING E3 LIGASE SUBSTRATES IN PRIMARY T CELLS}

As exemplified in many of the specific ligase/DUB-substrate relationships described above, the post-translational attachment of ubiquitin to cellular proteins can alter their function and half-life in diverse ways, thereby profoundly impacting 
$\mathrm{T}$ cell signaling and function. Targeted approaches in T cells, such as knockout/knockdown or over-expression of E3 ubiquitin ligases/DUBs, have aided in our understanding of how ubiquitylation affects specific cellular processes, such as $\mathrm{T}$ cell activation or effector function, and identified many specific protein substrates targeted by the ubiquitylation cascade during T cell signaling. However, these targeted approaches are limited in scope, and many fail to identify any specific substrate of ubiquitylation that is affected in the absence of the E3 ligase or DUB of interest.

While many specific E3 ubiquitin ligase and DUBs have been identified that impact immune function, as our review of the literature indicates there are relatively few (if any) identified substrates of these ligases and DUBs. Indeed, the majority of known ubiquitylation targets in T cells are attributed to function of only a handful of well-studied E3 ligases in which there is a robust immune phenotype in loss-of-function mouse models. Furthermore, targeted studies of ubiquitylation enzymes typically describe a single substrate that is altered in the absence of the E3 ligase or DUB; in most cases, it is exceedingly unlikely that altered ubiquitylation status of a single protein would be sufficient to explain a complex immunological phenotype. In this regard, high-throughput analysis of changes in ubiquitylation of many potential targets would be exceedingly beneficial both in new substrate discovery and in validation of previous findings.

Genomic and transcriptomic analyses of T cells lacking these various proteins are likely to suggest only indirect effects, i.e., downstream of changes that result from alterations in a substrate protein's levels or function. Proteomics, specifically the analysis of proteins using mass spectrometry, is the logical high-throughput method for studying post-translational modifications. Proteomic analysis of phosphorylation sites has been used with great success to catalog dynamic changes in phosphorylation that occur within minutes of T cell stimulation (22-28). Similarly, in the ubiquitylation field, proteomics has recently become de rigueur for global analysis of ubiquitylation sites and for substrate identification, although this has yet to translate to immunology.

Two general strategies have been used for high-throughput substrate identification. Candidate substrates can be identified based on observing interaction with the E3 ligase/DUB of interest, or a more global analysis can be performed to catalog thousands of ubiquitylated proteins, some of which may be changed in abundance in the absence or presence of a specific ubiquitylation enzyme. These are both mass spectrometry-based approaches that require high protein input. This presents a unique challenge for immunologists dealing with the limiting quantities of protein that can be obtained from primary lymphocytes. While limited studies have been done to date in primary $\mathrm{T}$ cells, ubiquitinspecific proteomic methods can be adapted for primary cells. In Figure 3, we have schematized several strategies, described below, for probing ubiquitylation in primary T cells via LC-MS/ MS-based approaches.

The simplest proteomic approach to indirectly identify effects of perturbations in the ubiquitylation cascade is to compare levels of protein in experimental and control cells by LC-MS/MS analysis (Figure 3A). Such whole proteome analyses have been performed successfully on unmanipulated primary mouse and human cells
(179-181), though not to probe explicitly for ubiquitylated proteins. This proteomic approach needs to be paired with control experiments to dissect transcriptional vs. post-transcriptional/ translational effects. As ubiquitylation does more than lead to degradation of substrate proteins, altered protein abundance for specific substrates between experimental and control cells may not be observed. In this regard, reconstruction of a "virtual western blot" to identify polyubiquitin or ubiquitin-like chains on substrates by observing mass shifts in gel fractionated LC-MS/MS datasets may have some utility (182). Analysis of relative protein abundance is an important technique that is readily applicable to immune cells, as it requires little starting material to achieve good depth of proteome coverage and reproducible quantification of protein abundance. Although the detection of peptides from any given protein is dependent on the sample fractionation, the protein size, and trypsin (or other protease) cleavage sites, this type of relative abundance measurement can provide important insights into the relative expression of E3 ligases or DUBs as well as how abundance of these proteins are altered in distinct $\mathrm{T}$ cell subsets or under various $\mathrm{T}$ cell stimulation conditions.

A common approach to identify active ubiquitylation enzymes and their ubiquitylated substrates is to express epitope-tagged versions of ubiquitin (Figure 3C) or the enzyme of interest (Figure 3D). After immunoprecipitation against the tag, ubiquitylated proteins or proteins in complex are analyzed by LC-MS/ MS to identify potential substrates that co-precipitated with the E3 ligase or ubiquitin itself $(183,184)$. If tagged ubiquitin is used, cell lysis and subsequent enrichment for ubiquitin can be carried out under harsh conditions, thereby minimizing detection of proteins that might not be directly modified by ubiquitin. For E3 ligase immunoprecipitations, which must be done under less stringent lysis conditions, identification of co-precipitating proteins can be coupled with in vitro ubiquitylation assays of bound proteins to identify putative substrates from non-substrate interaction partners. As substrate interactions may be fleeting, a more robust approach is to express a mutated "substratetrapping" form of the ligase, which has been done successfully for SCF ligase complexes in cell lines (185). In most cases, this type of approach requires transfection/transduction, making it less feasible for primary immune cell applications, particularly in analysis of naïve cells. Utilization of CRISPR technology to engineer mice with epitope-tagged E3 ligases or ubiquitin may make these types of experiments more accessible for primary cell studies.

Alternative approaches exist for substrate screening based on modification by ubiquitin. In lieu of expressing tagged ubiquitin, enrichment of polyubiquitylated proteins from unmanipulated cells can be accomplished by using reagents containing linked ubiquitin-binding domains [such as tandem ubiquitin-binding entities (TUBEs), Figure 3B]. The linked ubiquitin-binding domains bind with high affinity to a variety of polyubiquitin chains, and can be used for affinity purification of endogenous polyubiquitylated proteins from unmanipulated cells (186-189). The ability to detect endogenous polyubiquitylated proteins via affinity purification makes ubiquitin-binding domains more attractive for use in primary cells. The use of reagents that bind polyubiquitin chains, as opposed to using tagged ubiquitin, can 


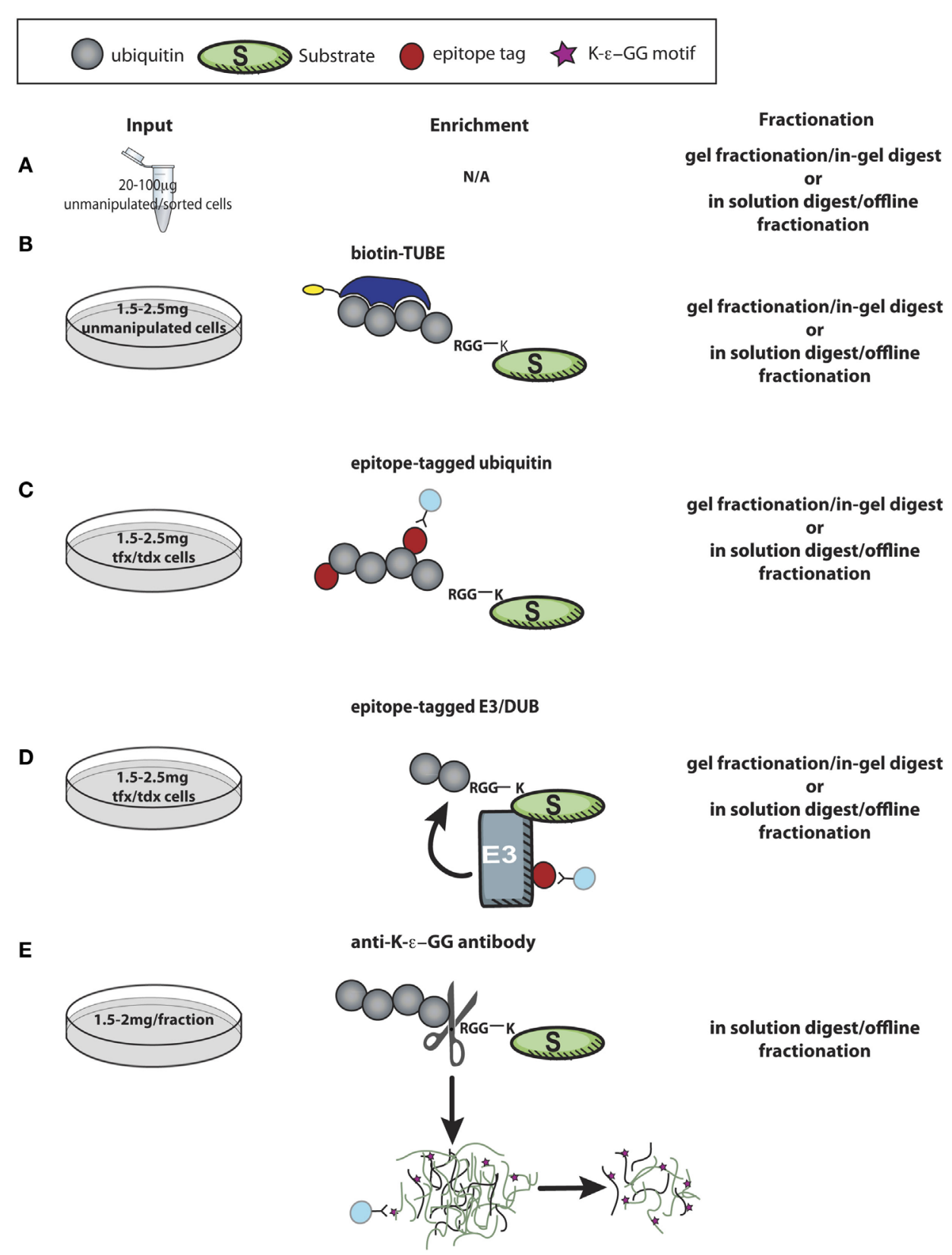

FIGURE 3 | Proteomic approaches to discover new targets of ubiquitin enzymes in T cells. (A) Using minimal protein from recovered after lysing unmanipulated primary cells, LC-MS/MS analysis of control and experimental cells is useful to screen for relative expression of thousands of proteins, allowing further pathway analysis and combination with other datasets to identify possible targets of ubiquitylation. (B,C) Enrichment of polyubiquitin chains using a tandem ubiquitin-binding entities (TUBEs) by immunoprecipitation of epitope-tagged ubiquitin identifies thousands of proteins that are either directly ubiquitylated or involved in ubiquitin complexes with relatively minimal cellular manipulation, and 1-2 mg of protein input. (D) More challenging in primary cells is expression of tagged E3 ligases or DUBs in primary cells to immunoprecipitate substrates, which may be bound only transiently and with low affinity to the enzyme of interest. (E) K- $\epsilon-G G$ peptide immunoprecipitation, perhaps the most direct proteomic approach to identify ubiquitylation, is challenging due to the large amount of starting material required (0.5-1 mg peptide/fraction). These approaches, and combinations there-of, hold great promise for future studies, both for hypothesis generation and investigations into molecular mechanisms of action for specific ubiquitylation enzymes. tfx $=$ transfected, tdx $=$ transduced.

be beneficial if researchers do not want to detect monoubiquitylation events. However, as with the use of tagged enzymes for immunoprecipitation, with these reagents validation of direct ubiquitylation on candidate protein substrates is required, as enrichment is carried out under less stringent lysis conditions and likely to identify many cellular ubiquitin-binding proteins and protein members of larger ubiquitylation complexes in addition to direct substrates of ubiquitylation. 
Ubiquitylation of a specific lysine can be directly observed by mass spectrometry. Lysines covalently modified by ubiquitin, or the ubiquitin-like proteins Nedd8 and ISG15 (UBLs), are protected from trypsin cleavage, and carry a diglycine, or ubiquitin remnant motif (K- $\epsilon-G G$ ) after trypsin cleavage at the C-terminal arginine of ubiquitin, Nedd8, or ISG15 (183). These peptides are relatively rare in proteome analyses, even following enrichment on ubiquitin ( $0.5-1 \%$ of proteins identified) (183). Development of an antibody against the ubiquitin remnant motif has revolutionized the ability to catalog ubiquitylated lysines. Direct immunoprecipitation of K- $\epsilon-G G$ peptides after enrichment on tagged ubiquitin significantly enriches the percent and number of ubiquitylated lysines and proteins identified compared to affinity purification of ubiquitin alone (190). The initial report using a monoclonal $\alpha \mathrm{K}-\epsilon-\mathrm{GG}$ antibody characterized only several hundred ubiquitin remnant peptides in a similar number of proteins; however, this effectively doubled the known number of ubiquitin-modified lysines in the human proteome (190). Subsequent studies, also in cell lines, have significantly improved upon this. By omitting the tagged ubiquitin affinity purification step and using direct antibody enrichment of trypsinized proteins from unmanipulated cells (Figure 3E), several labs report 5000 to 20,000 ubiquitylation sites identified in several thousand proteins within a single experiment (191-193). This ubiquitin remnant "profiling" has made ubiquitylation the second most abundant post-translational modification annotated in the human proteome (second only to phosphorylation) (192). Furthermore, it has been used quantitatively to successfully identify substrates of E3 ligases $(133,191)$. Thus far, however, no one has reported use of ubiquitin remnant profiling in primary T cells. Large amounts of starting protein material are required for highly specific enrichment of ubiquitin peptides, representing a significant hurdle for those interested in applying this technique in T cells. However, the benefits of observing a protein with a modified lysine are clear. As an example of one advantage of this method, recently, it was reported that a lysine in RIPK3, discovered via ubiquitin remnant immunoprecipitation from control and $A 20^{-/-} \mathrm{MEFs}$, was required for in vivo RIPK3 ubiquitylation in T cells (174). Thus, characterization of ubiquitylated lysine residues has ready application for immune cell biology.

Demonstrating the power of combination approaches, recently it was shown that expression of TUBEs in cells protects effectively against DUB activity. Following direct affinity purification of the TUBE construct from cells, tryptic peptides were subjected to diglycine immunoprecipitation, and a significant increase in ubiquitin remnant peptides was observed thanks to the protection of a variety of ubiquitin chains from DUB action. This method was successfully used to identify substrates of a previously uncharacterized F-box protein (133). However, this method requires transfection of the ubiquitin-binding TUBE construct as well as the ligase of interest, and therefore will require significant optimization before achieving utility in primary $\mathrm{T}$ cells.

For all ubiquitin-based enrichment techniques, it is common to include proteasomal inhibitors, such as MG132, in cell culture prior to LC-MS/MS analysis. However, use of these inhibitors carries important caveats. First, during $\mathrm{T}$ cell stimulation, degradative events may be critical for additional activation signaling to occur. Second, use of these inhibitors creates ubiquitin-proteasomal stress, and, while it is predicted that only about $6 \%$ of all $\mathrm{K}-\mathrm{\epsilon}-\mathrm{GG}$ peptides come from UBL linkages, use of inhibitors can lead to the depletion of free ubiquitin and an increased entry of UBLs into the ubiquitin conjugation cascade (191). Finally, in comparison to efficient protection against DUB activity, pharmacological inhibition of the proteasome may only incrementally increase the pool of ubiquitylated proteins in a cell, preferentially promoting a build-up of proteins with K48 polyubiquitylation (133).

Unlike the E3 ligases, where screens seek to identify substrates, unbiased screens for DUBs have relied primarily on activity profiling using chemical probes to identify isopeptidase activity of DUBs in cell lysates (194-199). Such probes can also be used to tag ubiquitin conjugating enzyme activity. Activity-based assays for E3 ligases utilize ubiquitylation in vitro to define new substrates. These assays are often dependent on recombinant expression of a range of possible substrates, and therefore more suited to specific hypothesis testing. Although there are commercially available protein microarrays suitable for discovery purposes, these currently exist in a large-scale format only for human proteins $(200,201)$. For both E3 ligases and DUBs, many of which are characterized as such by domain homology, activity profiling generates important data on the relevance of enzymatic activity in cells.

\section{CONCLUSION}

Ubiquitylation is a post-translational modification with critical roles in immune cell homeostasis and function that are only now being elucidated. Far from leading only to the degradation of proteins as part of cellular "maintenance," ubiquitylation of target substrates can have varied consequences on protein activity, localization, and half-life. The type of ubiquitin modification and also the availability of ubiquitin-binding proteins and DUBs, which cooperate with or antagonize E3 ubiquitin ligases, dictate these diverse consequences. In this review, we have described what is currently known about E3 ubiquitin ligases and DUBs that regulate TCR signaling and T cell biology. Where possible, we have indicated the molecular mechanism by which these proteins are thought to exert effects on TCR signaling, specifically in the activated $\mathrm{CD} 4^{+} \mathrm{T}$ cells. However, for the majority of these proteins, the molecular mechanism(s) by which they impact $\mathrm{T}$ cell signaling, or the immune system more broadly, remains unknown. Indeed, in some cases, it is still unclear whether the E3 ligase or DUB in question is acting via its ligase/DUB domains, as structure-function assays are largely lacking in $\mathrm{T}$ cells. We propose that proteomics techniques can be used in primary $\mathrm{T}$ cells to aid both hypothesis driven and exploratory experiments. Such studies will provide a more thorough understanding of how ubiquitylation pathways regulate TCR and other signaling pathways in $\mathrm{CD}^{+} \mathrm{T}$ cells and guide the rational design of therapeutics with which to treat immune-mediated diseases.

\section{AUTHOR CONTRIBUTIONS}
$\mathrm{EL}, \mathrm{PO}$, and $\mathrm{CO}$ wrote and edited this review. 


\section{REFERENCES}

1. Curtsinger JM, Mescher MF. Inflammatory cytokines as a third signal for T cell activation. Curr Opin Immunol (2010) 22:333-40. doi:10.1016/j.coi.2010.02.013

2. O'Shea JJ, Paul WE. Mechanisms underlying lineage commitment and plasticity of helper CD4+ T cells. Science (2010) 327:1098-102. doi:10.1126/ science. 1178334

3. Hubo M, Trinschek B, Kryczanowsky F, Tuettenberg A, Steinbrink K, Jonuleit $\mathrm{H}$. Costimulatory molecules on immunogenic versus tolerogenic human dendritic cells. Front Immunol (2013) 4:82. doi:10.3389/fimmu. 2013.00082

4. Tubo NJ, Jenkins MK. TCR signal quantity and quality in CD4 T cell differentiation. Trends Immunol (2014) 35:591-6. doi:10.1016/j.it.2014.09.008

5. Benczik M, Gaffen SL. The interleukin (IL)-2 family cytokines: survival and proliferation signaling pathways in T lymphocytes. Immunol Invest (2004) 33:109-42. doi:10.1081/IMM-120030732

6. Brownlie RJ, Zamoyska R. T cell receptor signalling networks: branched, diversified and bounded. Nat Rev Immunol (2013) 13:257-69. doi:10.1038/ nri3403

7. Zikherman J, Au-Yeung B. The role of $\mathrm{T}$ cell receptor signaling thresholds in guiding $\mathrm{T}$ cell fate decisions. Curr Opin Immunol (2015) 33:43-8. doi:10.1016/j.coi.2015.01.012

8. Komander D. The emerging complexity of protein ubiquitination. Biochem Soc Trans (2009) 37:937-53. doi:10.1042/bst0370937

9. Kulathu Y, Komander D. Atypical ubiquitylation - the unexplored world of polyubiquitin beyond Lys48 and Lys63 linkages. Nat Rev Mol Cell Biol (2012) 13:508-23. doi:10.1038/nrm3394

10. Friend SF, Deason-Towne F, Peterson LK, Berger AJ, Dragone LL. Regulation of T cell receptor complex-mediated signaling by ubiquitin and ubiquitin-like modifications. Am J Clin Exp Immunol (2014) 3:107-23.

11. Park Y, Jin HS, Aki D, Lee J, Liu YC. The ubiquitin system in immune regulation. Adv Immunol (2014) 124:17-66. doi:10.1016/ b978-0-12-800147-9.00002-9

12. Clague MJ, Heride C, Urbe S. The demographics of the ubiquitin system. Trends Cell Biol (2015) 25(7):417-26. doi:10.1016/j.tcb.2015.03.002

13. Ardley HC, Robinson PA. E3 ubiquitin ligases. Essays Biochem (2005) 41:15-30. doi:10.1042/eb0410015

14. Rotin D, Kumar S. Physiological functions of the HECT family of ubiquitin ligases. Nat Rev Mol Cell Biol (2009) 10:398-409. doi:10.1038/nrm2690

15. Wenzel DM, Lissounov A, Brzovic PS, Klevit RE. UBCH7 reactivity profile reveals Parkin and HHARI to be RING/HECT hybrids. Nature (2011) 474:105-8. doi:10.1038/nature09966

16. Dikic I, Wakatsuki S, Walters KJ. Ubiquitin-binding domains - from structures to functions. Nat Rev Mol Cell Biol (2009) 10:659-71. doi:10.1038/ nrm 2767

17. Iwai K, Tokunaga F. Linear polyubiquitination: a new regulator of NF-kappaB activation. EMBO Rep (2009) 10:706-13. doi:10.1038/embor.2009.144

18. Xu P, Duong DM, Seyfried NT, Cheng D, Xie Y, Robert J, et al. Quantitative proteomics reveals the function of unconventional ubiquitin chains in proteasomal degradation. Cell (2009) 137:133-45. doi:10.1016/j.cell.2009.01.041

19. Komander D, Rape M. The ubiquitin code. Annu Rev Biochem (2012) 81:203-29. doi:10.1146/annurev-biochem-060310-170328

20. Komander D, Clague MJ, Urbe S. Breaking the chains: structure and function of the deubiquitinases. Nat Rev Mol Cell Biol (2009) 10:550-63. doi:10.1038/ nrm2731

21. Monia BP, Ecker DJ, Jonnalagadda S, Marsh J, Gotlib L, Butt TR, et al. Gene synthesis, expression, and processing of human ubiquitin carboxyl extension proteins. J Biol Chem (1989) 264:4093-103.

22. Brockmeyer C, Paster W, Pepper D, Tan CP, Trudgian DC, McGowan S, et al. $\mathrm{T}$ cell receptor (TCR)-induced tyrosine phosphorylation dynamics identifies THEMIS as a new TCR signalosome component. J Biol Chem (2011) 286:7535-47. doi:10.1074/jbc.M110.201236

23. Navarro MN, Goebel J, Feijoo-Carnero C, Morrice N, Cantrell DA. Phosphoproteomic analysis reveals an intrinsic pathway for the regulation of histone deacetylase 7 that controls the function of cytotoxic T lymphocytes. Nat Immunol (2011) 12:352-61. doi:10.1038/ni.2008
24. Salek M, McGowan S, Trudgian DC, Dushek O, de Wet B, Efstathiou G, et al. Quantitative phosphoproteome analysis unveils LAT as a modulator of CD3zeta and ZAP-70 tyrosine phosphorylation. PLoS One (2013) 8:e77423. doi:10.1371/journal.pone.0077423

25. Chylek LA, Akimov V, Dengjel J, Rigbolt KT, Hu B, Hlavacek WS, et al. Phosphorylation site dynamics of early T-cell receptor signaling. PLoS One (2014) 9:e104240. doi:10.1371/journal.pone.0104240

26. Navarro MN, Goebel J, Hukelmann JL, Cantrell DA. Quantitative phosphoproteomics of cytotoxic T cells to reveal protein kinase $\mathrm{d} 2 \mathrm{regu}$ lated networks. Mol Cell Proteomics (2014) 13:3544-57. doi:10.1074/mcp. M113.037242

27. Roncagalli R, Hauri S, Fiore F, Liang Y, Chen Z, Sansoni A, et al. Quantitative proteomics analysis of signalosome dynamics in primary $\mathrm{T}$ cells identifies the surface receptor CD6 as a Lat adaptor-independent TCR signaling hub. Nat Immunol (2014) 15:384-92. doi:10.1038/ni.2843

28. Ji Q, Ding Y, Salomon AR. SRC homology 2 domain-containing leukocyte phosphoprotein of $76 \mathrm{kDa}$ (SLP-76) N-terminal tyrosine residues regulate a dynamic signaling equilibrium involving feedback of proximal T-cell receptor (TCR) signaling. Mol Cell Proteomics (2015) 14:30-40. doi:10.1074/ mcp.M114.037861

29. Bachmaier K, Krawczyk C, Kozieradzki I, Kong YY, Sasaki T, Oliveirados-Santos A, et al. Negative regulation of lymphocyte activation and autoimmunity by the molecular adaptor Cbl-b. Nature (2000) 403:211-6. doi: $10.1038 / 35003228$

30. Chiang YJ, Kole HK, Brown K, Naramura M, Fukuhara S, Hu RJ, et al. Cbl-b regulates the CD28 dependence of T-cell activation. Nature (2000) 403:216-20. doi:10.1038/35003235

31. Joazeiro CA, Wing SS, Huang H, Leverson JD, Hunter T, Liu YC. The tyrosine kinase negative regulator $\mathrm{c}$ - $\mathrm{Cbl}$ as a RING-type, E2-dependent ubiquitin-protein ligase. Science (1999) 286:309-12. doi:10.1126/ science.286.5438.309

32. Zheng N, Wang P, Jeffrey PD, Pavletich NP. Structure of a c-Cbl-UbcH7 complex: RING domain function in ubiquitin-protein ligases. Cell (2000) 102:533-9. doi:10.1016/S0092-8674(00)00057-X

33. Schmidt MH, Dikic I. The Cbl interactome and its functions. Nat Rev Mol Cell Biol (2005) 6:907-18. doi:10.1038/nrm1762

34. Staub O, Rotin D. Role of ubiquitylation in cellular membrane transport. Physiol Rev (2006) 86:669-707. doi:10.1152/physrev.00020.2005

35. Liu YC, Gu H. Cbl and Cbl-b in T-cell regulation. Trends Immunol (2002) 23:140-3. doi:10.1016/S1471-4906(01)02157-3

36. Jeon MS, Atfield A, Venuprasad K, Krawczyk C, Sarao R, Elly C, et al. Essential role of the E3 ubiquitin ligase Cbl-b in T cell anergy induction. Immunity (2004) 21:167-77. doi:10.1016/j.immuni.2004.07.013

37. Heissmeyer V, Macian F, Im SH, Varma R, Feske S, Venuprasad K, et al. Calcineurin imposes $\mathrm{T}$ cell unresponsiveness through targeted proteolysis of signaling proteins. Nat Immunol (2004) 5:255-65. doi:10.1038/ni1047

38. Fang D, Liu YC. Proteolysis-independent regulation of PI3K by Cbl-bmediated ubiquitination in T cells. Nat Immunol (2001) 2:870-5. doi:10.1038/ ni0901-870

39. Fang D, Wang HY, Fang N, Altman Y, Elly C, Liu YC. Cbl-b, a RING-type E3 ubiquitin ligase, targets phosphatidylinositol 3-kinase for ubiquitination in $\mathrm{T}$ cells. J Biol Chem (2001) 276:4872-8. doi:10.1074/jbc.M008901200

40. Yasuda T, Tezuka T, Maeda A, Inazu T, Yamanashi Y, Gu H, et al. Cbl-b positively regulates Btk-mediated activation of phospholipase C-gamma2 in B cells. J Exp Med (2002) 196:51-63. doi:10.1084/jem.20020068

41. Liu Q, Zhou H, Langdon WY, Zhang J. E3 ubiquitin ligase Cbl-b in innate and adaptive immunity. Cell Cycle (2014) 13:1875-84. doi:10.4161/ cc. 29213

42. Naramura M, Kole $\mathrm{HK}, \mathrm{Hu}$ RJ, Gu H. Altered thymic positive selection and intracellular signals in Cbl-deficient mice. Proc Natl Acad Sci U S A (1998) 95:15547-52. doi:10.1073/pnas.95.26.15547

43. Thien CB, Langdon WY. c-Cbl: a regulator of $\mathrm{T}$ cell receptor-mediated signalling. Immunol Cell Biol (1998) 76:473-82. doi:10.1046/j.1440-1711 1998.00768.x

44. Wang HY, Altman Y, Fang D, Elly C, Dai Y, Shao Y, et al. Cbl promotes ubiquitination of the $\mathrm{T}$ cell receptor zeta through an adaptor function of Zap-70. J Biol Chem (2001) 276:26004-11. doi:10.1074/jbc.M010738200 
45. Kadlecek TA, van Oers NS, Lefrancois L, Olson S, Finlay D, Chu DH, et al. Differential requirements for ZAP-70 in TCR signaling and T cell development. J Immunol (1998) 161:4688-94.

46. Myers MD, Sosinowski T, Dragone LL, White C, Band H, Gu H, et al. Src-like adaptor protein regulates TCR expression on thymocytes by linking the ubiquitin ligase c-Cbl to the TCR complex. Nat Immunol (2006) 7:57-66. doi: $10.1038 /$ ni1291

47. Tang J, Sawasdikosol S, Chang JH, Burakoff SJ. SLAP, a dimeric adapter protein, plays a functional role in T cell receptor signaling. Proc Natl Acad Sci U S A (1999) 96:9775-80. doi:10.1073/pnas.96.17.9775

48. Sosinowski T, Pandey A, Dixit VM, Weiss A. Src-like adaptor protein (SLAP) is a negative regulator of T cell receptor signaling. J Exp Med (2000) 191:463-74. doi:10.1084/jem.191.3.463

49. Sosinowski $\mathrm{T}$, Killeen $\mathrm{N}$, Weiss A. The Src-like adaptor protein downregulates the $\mathrm{T}$ cell receptor on $\mathrm{CD} 4+\mathrm{CD} 8+$ thymocytes and regulates positive selection. Immunity (2001) 15:457-66. doi:10.1016/ S1074-7613(01)00195-9

50. Myers MD, Dragone LL, Weiss A. Src-like adaptor protein down-regulates T cell receptor (TCR)-CD3 expression by targeting TCRzeta for degradation. J Cell Biol (2005) 170:285-94. doi:10.1083/jcb.200501164

51. Dragone LL, Shaw LA, Myers MD, Weiss A. SLAP, a regulator of immunoreceptor ubiquitination, signaling, and trafficking. Immunol Rev (2009) 232:218-28. doi:10.1111/j.1600-065X.2009.00827.x

52. Ouchida R, Yamasaki S, Hikida M, Masuda K, Kawamura K, Wada A, et al. A lysosomal protein negatively regulates surface $\mathrm{T}$ cell antigen receptor expression by promoting CD3zeta-chain degradation. Immunity (2008) 29:33-43. doi:10.1016/j.immuni.2008.04.024

53. Kawai Y, Ouchida R, Yamasaki S, Dragone L, Tsubata T, Wang JY. LAPTM5 promotes lysosomal degradation of intracellular CD3zeta but not of cell surface CD3zeta. Immunol Cell Biol (2014) 92:527-34. doi:10.1038/ icb. 2014.18

54. Watanabe Y, Sasahara Y, Ramesh N, Massaad MJ, Yeng Looi C, Kumaki $\mathrm{S}$, et al. T-cell receptor ligation causes Wiskott-Aldrich syndrome protein degradation and F-actin assembly downregulation. J Allergy Clin Immunol (2013) 132:648.e-55.e. doi:10.1016/j.jaci.2013.03.046

55. Thien CB, Dagger SA, Steer JH, Koentgen F, Jansen ES, Scott CL, et al. c-Cbl promotes $\mathrm{T}$ cell receptor-induced thymocyte apoptosis by activating the phosphatidylinositol 3-kinase/Akt pathway. J Biol Chem (2010) 285:1096981. doi:10.1074/jbc.M109.094920

56. Roa NS, Ordonez-Rueda D, Chavez-Rios JR, Raman C, Garcia-Zepeda EA, Lozano F, et al. The carboxy-terminal region of CD5 is required for c-CBL mediated TCR signaling downmodulation in thymocytes. Biochem Biophys Res Commun (2013) 432:52-9. doi:10.1016/j.bbrc.2013.01.086

57. Naramura M, Jang IK, Kole H, Huang F, Haines D, Gu H. c-Cbl and Cbl-b regulate $\mathrm{T}$ cell responsiveness by promoting ligand-induced TCR down-modulation. Nat Immunol (2002) 3:1192-9. doi:10.1038/ni855

58. Magnifico A, Ettenberg S, Yang C, Mariano J, Tiwari S, Fang S, et al. WW domain HECT E3s target Cbl RING finger E3s for proteasomal degradation. J Biol Chem (2003) 278:43169-77. doi:10.1074/jbc.M308009200

59. Yang B, Gay DL, MacLeod MK, Cao X, Hala T, Sweezer EM, et al. Nedd4 augments the adaptive immune response by promoting ubiquitin-mediated degradation of Cbl-b in activated T cells. Nat Immunol (2008) 9:1356-63. doi:10.1038/ni.1670

60. Zhao Y, Guo H, Qiao G, Zucker M, Langdon WY, Zhang J. E3 ubiquitin ligase Cbl-b regulates thymic-derived CD4+CD25+ regulatory T cell development by targeting Foxp3 for ubiquitination. JImmunol (2015) 194:1639-45. doi:10.4049/jimmunol.1402434

61. Huibregtse JM, Scheffner M, Beaudenon S, Howley PM. A family of proteins structurally and functionally related to the E6-AP ubiquitin-protein ligase. Proc Natl Acad Sci U S A (1995) 92:2563-7. doi:10.1073/pnas.92.11.5249-a

62. Gay DL, Ramon H, Oliver PM. Cbl- and Nedd4-family ubiquitin ligases: balancing tolerance and immunity. Immunol Res (2008) 42:51-64. doi:10.1007/ s12026-008-8034-0

63. Yang B, Kumar S. Nedd4 and Nedd4-2: closely related ubiquitin-protein ligases with distinct physiological functions. Cell Death Differ (2010) 17:68-77. doi:10.1038/cdd.2009.84

64. Staub O, Dho S, Henry P, Correa J, Ishikawa T, McGlade J, et al. WW domains of Nedd 4 bind to the proline-rich PY motifs in the epithelial $\mathrm{Na}^{+}$channel deleted in Liddle's syndrome. EMBO J (1996) 15:2371-80.
65. Kamynina E, Debonneville C, Bens M, Vandewalle A, Staub O. A novel mouse Nedd4 protein suppresses the activity of the epithelial $\mathrm{Na}^{+}$channel. FASEB J (2001) 15:204-14. doi:10.1096/fi.00-0191com

66. Henry PC, Kanelis V, O’Brien MC, Kim B, Gautschi I, Forman-Kay J, et al. Affinity and specificity of interactions between Nedd4 isoforms and the epithelial Na+ channel. J Biol Chem (2003) 278:20019-28. doi:10.1074/jbc. M211153200

67. Snyder PM, Steines JC, Olson DR. Relative contribution of Nedd4 and Nedd4-2 to ENaC regulation in epithelia determined by RNA interference. J Biol Chem (2004) 279:5042-6. doi:10.1074/jbc.M312477200

68. Fouladkou F, Landry T, Kawabe H, Neeb A, Lu C, Brose N, et al. The ubiquitin ligase Nedd4-1 is dispensable for the regulation of PTEN stability and localization. Proc Natl Acad Sci U S A (2008) 105:8585-90. doi:10.1073/ pnas. 0803233105

69. Maddika S, Kavela S, Rani N, Palicharla VR, Pokorny JL, Sarkaria JN, et al. WWP2 is an E3 ubiquitin ligase for PTEN. Nat Cell Biol (2011) 13:728-33. doi:10.1038/ncb2240

70. Guo H, Qiao G, Ying H, Li Z, Zhao Y, Liang Y, et al. E3 ubiquitin ligase Cbl-b regulates Pten via Nedd 4 in T cells independently of its ubiquitin ligase activity. Cell Rep (2012) 1:472-82. doi:10.1016/j.celrep.2012.04.008

71. ScharschmidtE, Wegener E, Heissmeyer V, Rao A, Krappmann D. Degradation of Bcl10 induced by T-cell activation negatively regulates NF-kappa B signaling. Mol Cell Biol (2004) 24:3860-73. doi:10.1128/MCB.24.9.3860-3873.2004

72. Kimura T, Kawabe H, Jiang C, Zhang W, Xiang YY, Lu C, et al. Deletion of the ubiquitin ligase Nedd4L in lung epithelia causes cystic fibrosis-like disease. Proc Natl Acad Sci U S A (2011) 108:3216-21. doi:10.1073/pnas.1010334108

73. Heikamp EB, Patel CH, Collins S, Waickman A, Oh MH, Sun IH, et al. The AGC kinase SGK1 regulates TH1 and TH2 differentiation downstream of the mTORC2 complex. Nat Immunol (2014) 15:457-64. doi:10.1038/ni.2867

74. Chen A, Gao B, Zhang J, McEwen T, Ye SQ, Zhang D, et al. The HECT-type E3 ubiquitin ligase AIP2 inhibits activation-induced T-cell death by catalyzing EGR2 ubiquitination. Mol Cell Biol (2009) 29:5348-56. doi:10.1128/ mcb.00407-09

75. Perry WL, Hustad CM, Swing DA, O'Sullivan TN, Jenkins NA, Copeland NG. The itchy locus encodes a novel ubiquitin protein ligase that is disrupted in a18H mice. Nat Genet (1998) 18:143-6. doi:10.1038/ng0298-143

76. Fang D, Elly C, Gao B, Fang N, Altman Y, Joazeiro C, et al. Dysregulation of T lymphocyte function in itchy mice: a role for itch in TH2 differentiation. Nat Immunol (2002) 3:281-7. doi:10.1038/ni763

77. Oliver PM, Cao X, Worthen GS, Shi P, Briones N, MacLeod M, et al. Ndfip1 protein promotes the function of itch ubiquitin ligase to prevent $\mathrm{T}$ cell activation and T helper 2 cell-mediated inflammation. Immunity (2006) 25:929-40. doi:10.1016/j.immuni.2006.10.012

78. Qiu L, Joazeiro C, Fang N, Wang HY, Elly C, Altman Y, et al. Recognition and ubiquitination of Notch by itch, a hect-type E3 ubiquitin ligase. J Biol Chem (2000) 275:35734-7. doi:10.1074/jbc.M007300200

79. Matesic LE, Copeland NG, Jenkins NA. Itchy mice: the identification of a new pathway for the development of autoimmunity. Curr Top Microbiol Immunol (2008) 321:185-200. doi:10.1007/978-3-540-75203-5_9

80. Aki D, Liu YC. To go or not to go: the "itchy" effect on the destiny of hematopoietic stem cells. Cell Res (2011) 21:1161-3. doi:10.1038/cr.2011.95

81. Rathinam C, Matesic LE, Flavell RA. The E3 ligase itch is a negative regulator of the homeostasis and function of hematopoietic stem cells. Nat Immunol (2011) 12:399-407. doi:10.1038/ni.2021

82. Xiao N, Eto D, Elly C, Peng G, Crotty S, Liu YC. The E3 ubiquitin ligase Itch is required for the differentiation of follicular helper T cells. Nat Immunol (2014) 15:657-66. doi:10.1038/ni.2912

83. Lohr NJ, Molleston JP, Strauss KA, Torres-Martinez W, Sherman EA, Squires $\mathrm{RH}$, et al. Human ITCH E3 ubiquitin ligase deficiency causes syndromic multisystem autoimmune disease. Am J Hum Genet (2010) 86:447-53. doi:10.1016/j.ajhg.2010.01.028

84. Meroni G, Diez-Roux G. TRIM/RBCC, a novel class of 'single protein RING finger' E3 ubiquitin ligases. Bioessays (2005) 27:1147-57. doi:10.1002/bies.20304

85. Micale L, Chaignat E, Fusco C, Reymond A, Merla G. The tripartite motif: structure and function. Adv Exp Med Biol (2012) 770:11-25. doi:10.1007/978-1-4614-5398-7_2

86. Reymond A, Meroni G, Fantozzi A, Merla G, Cairo S, Luzi L, et al. The tripartite motif family identifies cell compartments. EMBO J (2001) 20:2140-51. doi:10.1093/emboj/20.9.2140 
87. Napolitano LM, Meroni G. TRIM family: pleiotropy and diversification through homomultimer and heteromultimer formation. IUBMB Life (2012) 64:64-71. doi:10.1002/iub.580

88. Sardiello M, Cairo S, Fontanella B, Ballabio A, Meroni G. Genomic analysis of the TRIM family reveals two groups of genes with distinct evolutionary properties. BMC Evol Biol (2008) 8:225. doi:10.1186/1471-2148-8-225

89. Marin I. Origin and diversification of TRIM ubiquitin ligases. PLoS One (2012) 7:e50030. doi:10.1371/journal.pone.0050030

90. Zou W, Zhang DE. The interferon-inducible ubiquitin-protein isopeptide ligase (E3) EFP also functions as an ISG15 E3 ligase. J Biol Chem (2006) 281:3989-94. doi:10.1074/jbc.M510787200

91. Chu Y, Yang X. SUMO E3 ligase activity of TRIM proteins. Oncogene (2011) 30:1108-16. doi:10.1038/onc.2010.462

92. Napolitano LM, Jaffray EG, Hay RT, Meroni G. Functional interactions between ubiquitin E2 enzymes and TRIM proteins. Biochem J (2011) 434:309-19. doi:10.1042/bj20101487

93. Gack MU, Shin YC, Joo CH, Urano T, Liang C, Sun L, et al. TRIM25 RINGfinger E3 ubiquitin ligase is essential for RIG-I-mediated antiviral activity. Nature (2007) 446:916-20. doi:10.1038/nature05732

94. Tsuchida T, Zou J, Saitoh T, Kumar H, Abe T, Matsuura Y, et al. The ubiquitin ligase TRIM56 regulates innate immune responses to intracellular double-stranded DNA. Immunity (2010) 33:765-76. doi:10.1016/j. immuni.2010.10.013

95. Shen Y, Li NL, Wang J, Liu B, Lester S, Li K. TRIM56 is an essential component of the TLR3 antiviral signaling pathway. J Biol Chem (2012) 287:36404-13. doi:10.1074/jbc.M112.397075

96. Zhao W, Wang L, Zhang M, Wang P, Yuan C, Qi J, et al. Tripartite motif-containing protein 38 negatively regulates TLR3/4- and RIG-I-mediated IFNbeta production and antiviral response by targeting NAP1. J Immunol (2012) 188:5311-8. doi:10.4049/jimmunol.1103506

97. Zhao W, Wang L, Zhang M, Yuan C, Gao C. E3 ubiquitin ligase tripartite motif 38 negatively regulates TLR-mediated immune responses by proteasomal degradation of TNF receptor-associated factor 6 in macrophages. J Immunol (2012) 188:2567-74. doi:10.4049/jimmunol.1103255

98. Zurek B, Schoultz I, Neerincx A, Napolitano LM, Birkner K, Bennek E, et al. TRIM27 negatively regulates NOD2 by ubiquitination and proteasomal degradation. PLoS One (2012) 7:e41255. doi:10.1371/journal.pone.0041255

99. Qiu H, Huang F, Xiao H, Sun B, Yang R. TRIM22 inhibits the TRAF6stimulated NF-kappaB pathway by targeting TAB2 for degradation. Virol Sin (2013) 28:209-15. doi:10.1007/s12250-013-3343-4

100. Narayan K, Waggoner L, Pham ST, Hendricks GL, Waggoner SN, Conlon J, et al. TRIM13 is a negative regulator of MDA5-mediated type I interferon production. J Virol (2014) 88:10748-57. doi:10.1128/jvi.02593-13

101. Rajsbaum R, Versteeg GA, Schmid S, Maestre AM, Belicha-Villanueva A, Martinez-Romero C, et al. Unanchored K48-linked polyubiquitin synthesized by the E3-ubiquitin ligase TRIM6 stimulates the interferon-IKKepsilon kinase-mediated antiviral response. Immunity (2014) 40:880-95. doi:10.1016/j.immuni.2014.04.018

102. Weng L, Mitoma H, Trichot C, Bao M, Liu Y, Zhang Z, et al. The E3 ubiquitin ligase tripartite motif 33 is essential for cytosolic RNA-induced NLRP3 inflammasome activation. J Immunol (2014) 193:3676-82. doi:10.4049/ jimmunol.1401448

103. Wynne C, Lazzari E, Smith S, McCarthy EM, Ni Gabhann J, Kallal LE, et al. TRIM68 negatively regulates IFN-beta production by degrading TRK fused gene, a novel driver of IFN-beta downstream of anti-viral detection systems. PLoS One (2014) 9:e101503. doi:10.1371/journal.pone.0101503

104. Ozato K, Shin DM, Chang TH, Morse HC III. TRIM family proteins and their emerging roles in innate immunity. Nat Rev Immunol (2008) 8:849-60. doi: $10.1038 /$ nri2413

105. Versteeg GA, Rajsbaum R, Sanchez-Aparicio MT, Maestre AM, Valdiviezo J, Shi M, et al. The E3-ligase TRIM family of proteins regulates signaling pathways triggered by innate immune pattern-recognition receptors. Immunity (2013) 38:384-98. doi:10.1016/j.immuni.2012.11.013

106. Rajsbaum R, Garcia-Sastre A, Versteeg GA. TRIMmunity: the roles of the TRIM E3-ubiquitin ligase family in innate antiviral immunity. J Mol Biol (2014) 426:1265-84. doi:10.1016/j.jmb.2013.12.005

107. Tomar D, Singh R. TRIM family proteins: emerging class of RING E3 ligases as regulator of NF-kappaB pathway. Biol Cell (2015) 107:22-40. doi:10.1111/ boc. 201400046
108. Chikuma S, Suita N, Okazaki IM, Shibayama S, Honjo T. TRIM28 prevents autoinflammatory T cell development in vivo. Nat Immunol (2012) 13:596-603. doi:10.1038/ni.2293

109. Zhou XF, Yu J, Chang M, Zhang M, Zhou D, Cammas F, et al. TRIM28 mediates chromatin modifications at the TCRalpha enhancer and regulates the development of T and natural killer T cells. Proc Natl Acad Sci U S A (2012) 109:20083-8. doi:10.1073/pnas.1214704109

110. Cai X, Srivastava S, Sun Y, Li Z, Wu H, Zuvela-Jelaska L, et al. Tripartite motif containing protein 27 negatively regulates CD4 $\mathrm{T}$ cells by ubiquitinating and inhibiting the class II PI3K-C2beta. Proc Natl Acad Sci U S A (2011) 108:20072-7. doi:10.1073/pnas.1111233109

111. Choi UY, Hur JY, Lee MS, Zhang Q, Choi WY, Kim LK, et al. Tripartite motif-containing protein 30 modulates TCR-activated proliferation and effector functions in CD4+ T cells. PLoS One (2014) 9:e95805. doi:10.1371/ journal.pone.0095805

112. Kong HJ, Anderson DE, Lee CH, Jang MK, Tamura T, Tailor P, et al. Cutting edge: autoantigen Ro52 is an interferon inducible E3 ligase that ubiquitinates IRF-8 and enhances cytokine expression in macrophages. J Immunol (2007) 179:26-30. doi:10.4049/jimmunol.179.1.26

113. Yoshimi R, Chang TH, Wang H, Atsumi T, Morse HC III, Ozato K. Gene disruption study reveals a nonredundant role for TRIM21/Ro52 in NF-kappaB-dependent cytokine expression in fibroblasts. J Immunol (2009) 182:7527-38. doi:10.4049/jimmunol.0804121

114. Higgs R, Lazzari E, Wynne C, Ni Gabhann J, Espinosa A, Wahren-Herlenius $\mathrm{M}$, et al. Self protection from anti-viral responses - Ro52 promotes degradation of the transcription factor IRF7 downstream of the viral toll-like receptors. PLoS One (2010) 5:e11776. doi:10.1371/journal.pone.0011776

115. Espinosa A, Dardalhon V, Brauner S, Ambrosi A, Higgs R, Quintana FJ, et al. Loss of the lupus autoantigen Ro52/Trim21 induces tissue inflammation and systemic autoimmunity by disregulating the IL-23-Th17 pathway. J Exp Med (2009) 206:1661-71. doi:10.1084/jem.20090585

116. Rajsbaum R, Stoye JP, O'Garra A. Type I interferon-dependent and -independent expression of tripartite motif proteins in immune cells. Eur J Immunol (2008) 38:619-30. doi:10.1002/eji.200737916

117. Zhao Y, Sun Y. Cullin-RING ligases as attractive anti-cancer targets. Curr Pharm Des (2013) 19:3215-25. doi:10.2174/13816128113199990300

118. Zhou W, Wei W, Sun Y. Genetically engineered mouse models for functional studies of SKP1-CUL1-F-box-protein (SCF) E3 ubiquitin ligases. Cell Res (2013) 23:599-619. doi:10.1038/cr.2013.44

119. Bulatov E, Ciulli A. Targeting Cullin-RING E3 ubiquitin ligases for drug discovery: structure, assembly and small-molecule modulation. Biochem J (2015) 467:365-86. doi:10.1042/bj20141450

120. Zheng N, Schulman BA, Song L, Miller JJ, Jeffrey PD, Wang P, et al. Structure of the Cul1-Rbx1-Skp1-F boxSkp2 SCF ubiquitin ligase complex. Nature (2002) 416:703-9. doi:10.1038/416703a

121. Lydeard JR, Schulman BA, Harper JW. Building and remodelling CullinRING E3 ubiquitin ligases. EMBO Rep (2013) 14:1050-61. doi:10.1038/ embor.2013.173

122. Kawaida R, Yamada R, Kobayashi K, Tokuhiro S, Suzuki A, Kochi Y, et al. CUL1, a component of E3 ubiquitin ligase, alters lymphocyte signal transduction with possible effect on rheumatoid arthritis. Genes Immun (2005) 6:194-202. doi:10.1038/sj.gene.6364177

123. Skaar JR, D’Angiolella V, Pagan JK, Pagano M. SnapShot: F box proteins II. Cell (2009) 137:1358,1358.e1351. doi:10.1016/j.cell.2009.05.040

124. Fuchs SY, Chen A, Xiong Y, Pan ZQ, Ronai Z. HOS, a human homolog of slimb, forms an SCF complex with Skp1 and Cullin1 and targets the phosphorylation-dependent degradation of IkappaB and beta-catenin. Oncogene (1999) 18:2039-46. doi:10.1038/sj.onc. 1202760

125. Kumar KGS, Tang W, Ravindranath AK, Clark WA, Croze E, Fuchs SY. SCF(HOS) ubiquitin ligase mediates the ligand-induced down-regulation of the interferon-alpha receptor. $E M B O J(2003)$ 22:5480-90. doi:10.1093/ emboj/cdg524

126. Nakayama K, Hatakeyama S, Maruyama S-I, Kikuchi A, Onoé K, Good RA, et al. Impaired degradation of inhibitory subunit of NF-kappa B (I kappa B) and beta-catenin as a result of targeted disruption of the betaTrCP1 gene. Proc Nat Acad Sci U S A (2003) 100:8752-7. doi:10.1073/ pnas. 1133216100

127. Appleman LJ, Chernova I, LI L, Boussiotis VA. CD28 costimulation mediates transcription of SKP2 and CKS1, the substrate recognition components of 
SCFSkp2 ubiquitin ligase that leads p27kip1 to degradation. Cell Cycle (2014) 5:2123-9. doi:10.4161/cc.5.18.3139

128. Mathew R, Seiler MP, Scanlon ST, Mao A-P, Constantinides MG, BertozziVilla C, et al. BTB-ZF factors recruit the E3 ligase cullin 3 to regulate lymphoid effector programs. Nature (2012) 491:618-21. doi:10.1038/nature11548

129. Mathew R, Mao AP, Chiang AH, Bertozzi-Villa C, Bunker JJ, Scanlon ST, et al. A negative feedback loop mediated by the Bcl6-cullin 3 complex limits Th cell differentiation. J Exp Med (2014) 211:1137-51. doi:10.1084/ jem.20132267

130. Yen HC, Elledge SJ. Identification of SCF ubiquitin ligase substrates by global protein stability profiling. Science (2008) 322:923-9. doi:10.1126/ science. 1160462

131. Emanuele MJ, Elia AE, Xu Q, Thoma CR, Izhar L, Leng Y, et al. Global identification of modular cullin-RING ligase substrates. Cell (2011) 147:459-74. doi:10.1016/j.cell.2011.09.019

132. Yumimoto K, Matsumoto M, Oyamada K, Moroishi T, Nakayama KI. Comprehensive identification of substrates for F-box proteins by differential proteomics analysis. J Proteome Res (2012) 11:3175-85. doi:10.1021/ pr201216u

133. Yoshida Y, Saeki Y, Murakami A, Kawawaki J, Tsuchiya H, Yoshihara H, et al. A comprehensive method for detecting ubiquitinated substrates using TR-TUBE. Proc Natl Acad Sci U S A (2015) 112:4630-5. doi:10.1073/ pnas. 1422313112

134. Lin JT, Lineberry NB, Kattah MG, Su LL, Utz PJ, Fathman CG, et al. Naive $\mathrm{CD} 4 \mathrm{t}$ cell proliferation is controlled by mammalian target of rapamycin regulation of GRAIL expression. J Immunol (2009) 182:5919-28. doi:10.4049/ jimmunol.0803986

135. Anandasabapathy N, Ford GS, Bloom D, Holness C, Paragas V, Seroogy C, et al. GRAIL: an E3 ubiquitin ligase that inhibits cytokine gene transcription is expressed in anergic CD4(+) T cells. Immunity (2003) 18:535-47. doi:10.1016/S1074-7613(03)00084-0

136. Schartner JM, Simonson WT, Wernimont SA, Nettenstrom LM, Huttenlocher A, Seroogy CM. Gene related to anergy in lymphocytes (GRAIL) expression in $\mathrm{CD}^{+} \mathrm{T}$ cells impairs actin cytoskeletal organization during $\mathrm{T}$ cell/ antigen-presenting cell interactions. J Biol Chem (2009) 284:34674-81. doi:10.1074/jbc.M109.024497

137. Kriegel MA, Rathinam C, Flavell RA. E3 ubiquitin ligase GRAIL controls primary T cell activation and oral tolerance. Proc Natl Acad Sci U S A (2009) 106:16770-5. doi:10.1073/pnas.0908957106

138. Nurieva RI, Zheng S, Jin W, Chung Y, Zhang Y, Martinez GJ, et al. The E3 ubiquitin ligase GRAIL regulates $\mathrm{T}$ cell tolerance and regulatory $\mathrm{T}$ cell function by mediating T cell receptor-CD3 degradation. Immunity (2010) 32:670-80. doi:10.1016/j.immuni.2010.05.002

139. Chang M, Jin W, Chang J-H, Xiao Y, Brittain GC, Yu J, et al. The ubiquitin ligase Peli1 negatively regulates $\mathrm{T}$ cell activation and prevents autoimmunity. Nat Immunol (2011) 12:1002-9. doi:10.1038/ni.2090

140. McDonough H, Patterson C. CHIP: a link between the chaperone and proteasome systems. Cell Stress Chaperones (2003) 8:303-8. doi:10.1379/1466-1268(2003)008<0303:CALBTC >2.0.CO;2

141. Schulman BA, Chen ZJ. Protein ubiquitination: CHIPping away the symmetry. Mol Cell (2005) 20:653-5. doi:10.1016/j.molcel.2005.11.019

142. Wang S, Li Y, Hu Y-H, Song R, Gao Y, Liu H-Y, et al. STUB1 is essential for T-cell activation by ubiquitinating CARMA1. Eur JImmunol (2013) 43:1034-41. doi:10.1002/eji.201242554

143. Chen Z, Barbi J, Bu S, Yang H-Y, Li Z, Gao Y, et al. The ubiquitin ligase Stub1 negatively modulates regulatory $\mathrm{T}$ cell suppressive activity by promoting degradation of the transcription factor Foxp3. Immunity (2013) 39:272-85. doi:10.1016/j.immuni.2013.08.006

144. Wei Q, Sha Y, Bhattacharya A, Abdel Fattah E, Bonilla D, Jyothula SS, et al. Regulation of IL-4 receptor signaling by STUB1 in lung inflammation. Am J Respir Crit Care Med (2014) 189:16-29. doi:10.1164/ rccm.201305-0874OC

145. Lee NK, Lee SY. Modulation of life and death by the tumor necrosis factor receptor-associated factors (TRAFs). J Biochem Mol Biol (2002) 35:61-6. doi:10.5483/BMBRep.2002.35.1.061

146. Martinez-Forero I, Rouzaut A, Palazon A, Dubrot J, Melero I. Lysine 63 polyubiquitination in immunotherapy and in cancer-promoting inflammation. Clin Cancer Res (2009) 15:6751-7. doi:10.1158/1078-0432. ccr-09-1225
147. Sun L, Deng L, Ea C-K, Xia Z-P, Chen ZJ. The TRAF6 ubiquitin ligase and TAK1 kinase mediate IKK activation by BCL10 and MALT1 in T lymphocytes. Mol Cell (2004) 14:289-301. doi:10.1038/nri1379

148. Oeckinghaus A, Wegener E, Welteke V, Ferch U, Arslan SC, Ruland J, et al. Malt1 ubiquitination triggers NF-kappaB signaling upon T-cell activation. EMBO J (2007) 26:4634-45. doi:10.1038/sj.emboj.7601897

149. Bidère N, Snow AL, Sakai K, Zheng L, Lenardo MJ. Caspase-8 regulation by direct interaction with TRAF6 in T cell receptor-induced NF-kappaB activation. Curr Biol (2006) 16:1666-71. doi:10.1016/j.cub.2006.06.062

150. King CG, Kobayashi T, Cejas PJ, Kim T, Yoon K, Kim GK, et al. TRAF6 is a $\mathrm{T}$ cell-intrinsic negative regulator required for the maintenance of immune homeostasis. Nat Med (2006) 12:1088-92. doi:10.1038/nm1449

151. King CG, Buckler JL, Kobayashi T, Hannah JR, Bassett G, Kim T, et al. Cutting edge: requirement for TRAF6 in the induction of T cell anergy. J Immunol (2008) 180:34-8. doi:10.4049/jimmunol.180.1.34

152. So T, Choi H, Croft M. OX40 complexes with phosphoinositide 3-kinase and protein kinase $\mathrm{B}(\mathrm{PKB})$ to augment TCR-dependent PKB signaling. J Immunol (2011) 186:3547-55. doi:10.4049/jimmunol.1003156

153. So T, Soroosh P, Eun S-Y, Altman A, Croft M. Antigen-independent signalosome of CARMA1, PKC , and TNF receptor-associated factor 2 (TRAF2) determines NF-KB signaling in T cells. Proc Natl Acad Sci U S A (2011) 108:2903-8. doi:10.1073/pnas.1008765108

154. Tsitsikov EN, Laouini D, Dunn IF, Sannikova TY, Davidson L, Alt FW, et al. TRAF1 is a negative regulator of TNF signaling. Enhanced TNF signaling in TRAF1-deficient mice. Immunity (2001) 15:647-57. doi:10.1016/ S1074-7613(01)00207-2

155. Xie P, Kraus ZJ, Stunz LL, Liu Y, Bishop GA. TNF receptor-associated factor 3 is required for T cell-mediated immunity and TCR/CD28 signaling. J Immunol (2011) 186:143-55. doi:10.4049/jimmunol.1000290

156. Yi Z, Stunz LL, Lin WW, Bishop GA. TRAF3 regulates homeostasis of CD8+ central memory T cells. PLoS One (2014) 9:e102120. doi:10.1371/journal. pone. 0102120

157. So T, Salek-Ardakani S, Nakano H, Ware CF, Croft M. TNF receptor-associated factor 5 limits the induction of Th2 immune responses. J Immunol (2004) 172:4292-7. doi:10.4049/jimmunol.172.7.4292

158. Nijman SM, Luna-Vargas MP, Velds A, Brummelkamp TR, Dirac AM, Sixma TK, et al. A genomic and functional inventory of deubiquitinating enzymes. Cell (2005) 123:773-86. doi:10.1016/j.cell.2005.11.007

159. Sowa ME, Bennett EJ, Gygi SP, Harper JW. Defining the human deubiquitinating enzyme interaction landscape. Cell (2009) 138:389-403. doi:10.1016/j. cell.2009.04.042

160. Eletr ZM, Wilkinson KD. Regulation of proteolysis by human deubiquitinating enzymes. Biochim Biophys Acta (2014) 1843:114-28. doi:10.1016/j. bbamcr.2013.06.027

161. Mouchantaf R, Azakir BA, McPherson PS, Millard SM, Wood SA, Angers A. The ubiquitin ligase itch is auto-ubiquitylated in vivo and in vitro but is protected from degradation by interacting with the deubiquitylating enzyme FAM/USP9X. J Biol Chem (2006) 281:38738-47. doi:10.1074/jbc. M605959200

162. Park Y, Jin H-S, Liu Y-C. Regulation of T cell function by the ubiquitinspecific protease USP9X via modulating the Carmal-Bcl10-Malt1 complex. Proc Natl Acad Sci U S A (2013) 110:9433-8. doi:10.1073/ pnas. 1221925110

163. Naik E, Webster JD, DeVoss J, Liu J, Suriben R, Dixit VM. Regulation of proximal $\mathrm{T}$ cell receptor signaling and tolerance induction by deubiquitinase Usp9X. J Exp Med (2014) 211:1947-55. doi:10.1084/jem.20140860

164. Zou Q, Jin J, Hu H, Li HS, Romano S, Xiao Y, et al. USP15 stabilizes MDM2 to mediate cancer-cell survival and inhibit antitumor $\mathrm{T}$ cell responses. Nat Immunol (2014) 15:562-70. doi:10.1038/ni.2885

165. van Loosdregt J, Fleskens V, Fu J, Brenkman AB, Bekker CP, Pals CE, et al. Stabilization of the transcription factor Foxp 3 by the deubiquitinase USP7 increases Treg-cell-suppressive capacity. Immunity (2013) 39:259-71. doi:10.1016/j.immuni.2013.05.018

166. Xie JJ, Liang JQ, Diao LH, Altman A, Li Y. TNFR-associated factor 6 regulates TCR signaling via interaction with and modification of LAT adapter. J Immunol (2013) 190:4027-36. doi:10.4049/jimmunol.1202742

167. Shembade N, Ma A, Harhaj EW. Inhibition of NF-kappaB signaling by A20 through disruption of ubiquitin enzyme complexes. Science (2010) 327:1135-9. doi:10.1126/science.1182364 
168. Harhaj EW, Dixit VM. Regulation of NF-kappaB by deubiquitinases. Immunol Rev (2012) 246:107-24. doi:10.1111/j.1600-065X.2012.01100.x

169. Lee EG, Boone DL, Chai S, Libby SL, Chien M, Lodolce JP, et al. Failure to regulate TNF-induced NF-kappaB and cell death responses in A20-deficient mice. Science (2000) 289:2350-4. doi:10.1126/ science. 289.5488.2350

170. Wertz IE, O'Rourke KM, Zhou H, Eby M, Aravind L, Seshagiri S, et al. De-ubiquitination and ubiquitin ligase domains of A20 downregulate NF-kappaB signalling. Nature (2004) 430:694-9. doi:10.1038/ nature 02794

171. Tewari M, Wolf FW, Seldin MF, O’Shea KS, Dixit VM, Turka LA. Lymphoid expression and regulation of A20, an inhibitor of programmed cell death. J Immunol (1995) 154:1699-706.

172. Duwel M, Welteke V, Oeckinghaus A, Baens M, Kloo B, Ferch U, et al. A20 negatively regulates $\mathrm{T}$ cell receptor signaling to NF-kappaB by cleaving Malt1 ubiquitin chains. JImmunol (2009) 182:7718-28. doi:10.4049/ jimmunol.0803313

173. De A, Dainichi T, Rathinam CV, Ghosh S. The deubiquitinase activity of A20 is dispensable for NF-kappaB signaling. EMBO Rep (2014) 15:775-83. doi:10.15252/embr.201338305

174. Onizawa M, Oshima S, Schulze-Topphoff U, Oses-Prieto JA, Lu T, Tavares R, et al. The ubiquitin-modifying enzyme A20 restricts ubiquitination of the kinase RIPK3 and protects cells from necroptosis. Nat Immunol (2015) 16:618-27. doi:10.1038/ni.3172

175. Kovalenko A, Chable-Bessia C, Cantarella G, Israel A, Wallach D, Courtois G. The tumour suppressor CYLD negatively regulates NF-kappaB signalling by deubiquitination. Nature (2003) 424:801-5. doi:10.1038/nature01802

176. Trompouki E, Hatzivassiliou E, Tsichritzis T, Farmer H, Ashworth A, Mosialos G. CYLD is a deubiquitinating enzyme that negatively regulates NF-kappaB activation by TNFR family members. Nature (2003) 424:793-6. doi:10.1038/nature01803

177. Reiley WW, Jin W, Lee AJ, Wright A, Wu X, Tewalt EF, et al. Deubiquitinating enzyme CYLD negatively regulates the ubiquitin-dependent kinase Tak1 and prevents abnormal T cell responses. J Exp Med (2007) 204:1475-85. doi:10.1084/jem.20062694

178. Ahmed N, Zeng M, Sinha I, Polin L, Wei WZ, Rathinam C, et al. The E3 ligase itch and deubiquitinase cyld act together to regulate Tak1 and inflammation. Nat Immunol (2011) 12:1176-83. doi:10.1038/ni.2157

179. Graessel A, Hauck SM, von Toerne C, Kloppmann E, Goldberg T, Koppensteiner $\mathrm{H}$, et al. A combined omics approach to generate the surface atlas of human naive $\mathrm{CD} 4^{+} \mathrm{T}$ cells during early $\mathrm{T}$-cell receptor activation. Mol Cell Proteomics (2015) 14:2085-102. doi:10.1074/mcp. M114.045690

180. Pagani M, Rockstroh M, Schuster M, Rossetti G, Moro M, Crosti M, et al. Reference proteome of highly purified human Th1 cells reveals strong effects on metabolism and protein ubiquitination upon differentiation. Proteomics (2015) 15(21):3644-7. doi:10.1002/pmic.201400139

181. Zanker D, Otto W, Chen W, von Bergen M, Tomm JM. Compartment resolved reference proteome map from highly purified naive, activated, effector, and memory CD8(+) murine immune cells. Proteomics (2015) 15:1808-12. doi:10.1002/pmic.201400405

182. Seyfried NT, Xu P, Duong DM, Cheng D, Hanfelt J, Peng J. Systematic approach for validating the ubiquitinated proteome. Anal Chem (2008) 80:4161-9. doi:10.1021/ac702516a

183. Peng J, Schwartz D, Elias JE, Thoreen CC, Cheng D, Marsischky G, et al. A proteomics approach to understanding protein ubiquitination. Nat Biotechnol (2003) 21:921-6. doi:10.1038/nbt849

184. Meierhofer D, Wang X, Huang L, Kaiser P. Quantitative analysis of global ubiquitination in HeLa cells by mass spectrometry. J Proteome Res (2008) 7:4566-76. doi:10.1021/pr800468j

185. Harper JW, Tan MK. Understanding cullin-RING E3 biology through proteomics-based substrate identification. Mol Cell Proteomics (2012) 11:1541-50. doi:10.1074/mcp.R112.021154

186. Hjerpe R, Aillet F, Lopitz-Otsoa F, Lang V, England P, Rodriguez MS. Efficient protection and isolation of ubiquitylated proteins using tandem ubiquitin-binding entities. EMBO Rep (2009) 10:1250-8. doi:10.1038/ embor.2009.192
187. Lopitz-Otsoa F, Rodriguez MS, Aillet F. Properties of natural and artificial proteins displaying multiple ubiquitin-binding domains. Biochem Soc Trans (2010) 38:40-5. doi:10.1042/bst0380040

188. Aillet F, Lopitz-Otsoa F, Hjerpe R, Torres-Ramos M, Lang V, Rodriguez MS. Isolation of ubiquitylated proteins using tandem ubiquitin-binding entities. Methods Mol Biol (2012) 832:173-83. doi:10.1007/978-1-61779-474-2_12

189. Lopitz-Otsoa F, Rodriguez-Suarez E, Aillet F, Casado-Vela J, Lang V, Matthiesen R, et al. Integrative analysis of the ubiquitin proteome isolated using tandem ubiquitin binding entities (TUBEs). J Proteomics (2012) 75:2998-3014. doi:10.1016/j.jprot.2011.12.001

190. Xu G, Paige JS, Jaffrey SR. Global analysis of lysine ubiquitination by ubiquitin remnant immunoaffinity profiling. Nat Biotechnol (2010) 28:868-73. doi:10.1038/nbt.1654

191. Kim W, Bennett EJ, Huttlin EL, Guo A, Li J, Possemato A, et al. Systematic and quantitative assessment of the ubiquitin-modified proteome. Mol Cell (2011) 44:325-40. doi:10.1016/j.molcel.2011.08.025

192. Wagner SA, Beli P, Weinert BT, Nielsen ML, Cox J, Mann M, et al. A proteome-wide, quantitative survey of in vivo ubiquitylation sites reveals widespread regulatory roles. Mol Cell Proteomics (2011) 10:M111.013284. doi:10.1074/mcp.M111.013284

193. Udeshi ND, Svinkina T, Mertins P, Kuhn E, Mani DR, Qiao JW, et al. Refined preparation and use of anti-diglycine remnant (K-epsilon-GG) antibody enables routine quantification of 10,000 s of ubiquitination sites in single proteomics experiments. Mol Cell Proteomics (2013) 12:825-31. doi:10.1074/ mcp.O112.027094

194. Borodovsky A, Ovaa H, Kolli N, Gan-Erdene T, Wilkinson KD, Ploegh HL, et al. Chemistry-based functional proteomics reveals novel members of the deubiquitinating enzyme family. Chem Biol (2002) 9:1149-59. doi:10.1016/ S1074-5521(02)00248-X

195. Hemelaar J, Galardy PJ, Borodovsky A, Kessler BM, Ploegh HL, Ovaa H. Chemistry-based functional proteomics: mechanism-based activity-profiling tools for ubiquitin and ubiquitin-like specific proteases. J Proteome Res (2004) 3:268-76. doi:10.1021/pr0341080

196. Fonovic M, Bogyo M. Activity-based probes as a tool for functional proteomic analysis of proteases. Expert Rev Proteomics (2008) 5:721-30. doi:10.1586/14789450.5.5.721

197. Love KR, Pandya RK, Spooner E, Ploegh HL. Ubiquitin C-terminal electrophiles are activity-based probes for identification and mechanistic study of ubiquitin conjugating machinery. ACS Chem Biol (2009) 4:275-87. doi:10.1021/cb9000348

198. de Jong A, Merkx R, Berlin I, Rodenko B, Wijdeven RH, El Atmioui D, et al. Ubiquitin-based probes prepared by total synthesis to profile the activity of deubiquitinating enzymes. Chembiochem (2012) 13:2251-8. doi:10.1002/ cbic. 201200497

199. Claessen JH, Witte MD, Yoder NC, Zhu AY, Spooner E, Ploegh HL. Catchand-release probes applied to semi-intact cells reveal ubiquitin-specific protease expression in Chlamydia trachomatis infection. Chembiochem (2013) 14:343-52. doi:10.1002/cbic.201200701

200. Persaud A, Alberts P, Amsen EM, Xiong X, Wasmuth J, Saadon Z, et al. Comparison of substrate specificity of the ubiquitin ligases Nedd4 and Nedd4-2 using proteome arrays. Mol Syst Biol (2009) 5:333. doi:10.1038/msb.2009.85

201. Persaud A, Rotin D. Use of proteome arrays to globally identify substrates for E3 ubiquitin ligases. Methods Mol Biol (2011) 759:215-24. doi:10.1007/978-1-61779-173-4_13

Conflict of Interest Statement: The authors declare that the research was conducted in the absence of any commercial or financial relationships that could be construed as a potential conflict of interest.

Copyright (c) 2015 O'Leary, Lewis and Oliver. This is an open-access article distributed under the terms of the Creative Commons Attribution License (CC BY). The use, distribution or reproduction in other forums is permitted, provided the original author(s) or licensor are credited and that the original publication in this journal is cited, in accordance with accepted academic practice. No use, distribution or reproduction is permitted which does not comply with these terms. 